\title{
Inter-group entrainment in Afro-Brazilian Congado ritual
}

\author{
GLAURA LUCAS \\ Universidade Federal de Minas Gerais \\ MARTIN CLAYTON \\ Durham University \\ LAURA LEANTE \\ Durham University
}

\begin{abstract}
This paper investigates the phenomenon of entrainment between independent groups of musicians in the context of Afro-Brazilian Congado performance. Based on audiovisual recordings made during a festival in May 2006, we present analyses of four different occasions during which two different groups play different music in close proximity to each other. The results indicate the occurrence of (a) entrainment in phase, (b) entrainment out of phase, and (c) no entrainment. These results are discussed in the particular ethnographic context, as well as with reference to existing literature on entrainment and interpersonal coordination.
\end{abstract}

Submitted 2010 November 26; accepted 2011 March 25.

KEYWORDS: entrainment, Congado, ethnography, Afro-Brazilian music, Brazil.

\section{INTRODUCTION}

A number of studies over the last fifteen years or so have begun to explore the significance of entrainment - the process by which independent but coupled rhythmical systems assume the same or related periods for the perception and performance of music. One approach, which developed from Jones's dynamical attending theory (Jones \& Boltz 1989), sees the perception of metre as founded on the entrainment of the listener's attentional rhythms to musical stimuli: this process has been modelled by Large and others and forms an important part of London's theory of metre (Eck, 2002; Large, 2000; Large \& Jones, 1999; Large $\&$ Kolen, 1994; London, 2004). Clayton et al. discussed further applications of this idea in music research, and in ethnomusicology in particular (2005), and Clayton (2007) explored unintentional entrainment in a performance of Indian classical music. However, to date, entrainment studies drawing on data from actual musical performances - unmediated by metronomes, click-tracks or other experimental interventions remain extremely rare (see however Doffman, 2008).

The present study explores entrainment in a context which has not been considered previously; that is, entrainment between independent groups of musicians. The groups in question are all participants in a form of Afro-Brazilian ritual performance known as Congado - a religious tradition widespread in the state of Minas Gerais, Brazil. There are different types of groups - e.g. Congo, Moçambique, and Candombe - each one having its own functions and associated with distinct uniforms, ritual objects, and musical instruments, and performing its own rhythms, dances, and songs throughout the whole ceremony (a Congo group is pictured in Figure 1). Each group typically comprises a lead singer, three drummers, three to six other percussionists, and up to 40 dancers who process either in two parallel lines (in Congo) or in a more compact formation (in Moçambique). Each group plays its own part in a larger ritual, and in this sense the groups cooperate in achieving the ritual's aims. At the same time, however, each has its own identity - linked to a home area or community and displayed through uniforms and banners - and it is also important for ritual purposes that the separate identity of each group is not compromised, especially when groups belonging to different communities come to perform at the same event. Extensive ethnographic research by Lucas (2002a, 2002b, 2005) has demonstrated that for participants the maintenance of boundaries between the different groups depends on sustaining a rhythmic difference. Since participants feel a tendency towards synchronization with other groups, resisting it becomes a demonstration of the group's spiritual power, which is expressed by its musical cohesion and competence. An important musical 
and ritual consideration for the groups is, therefore, the imperative to resist entrainment whenever groups belonging to different communities meet during the ritual.

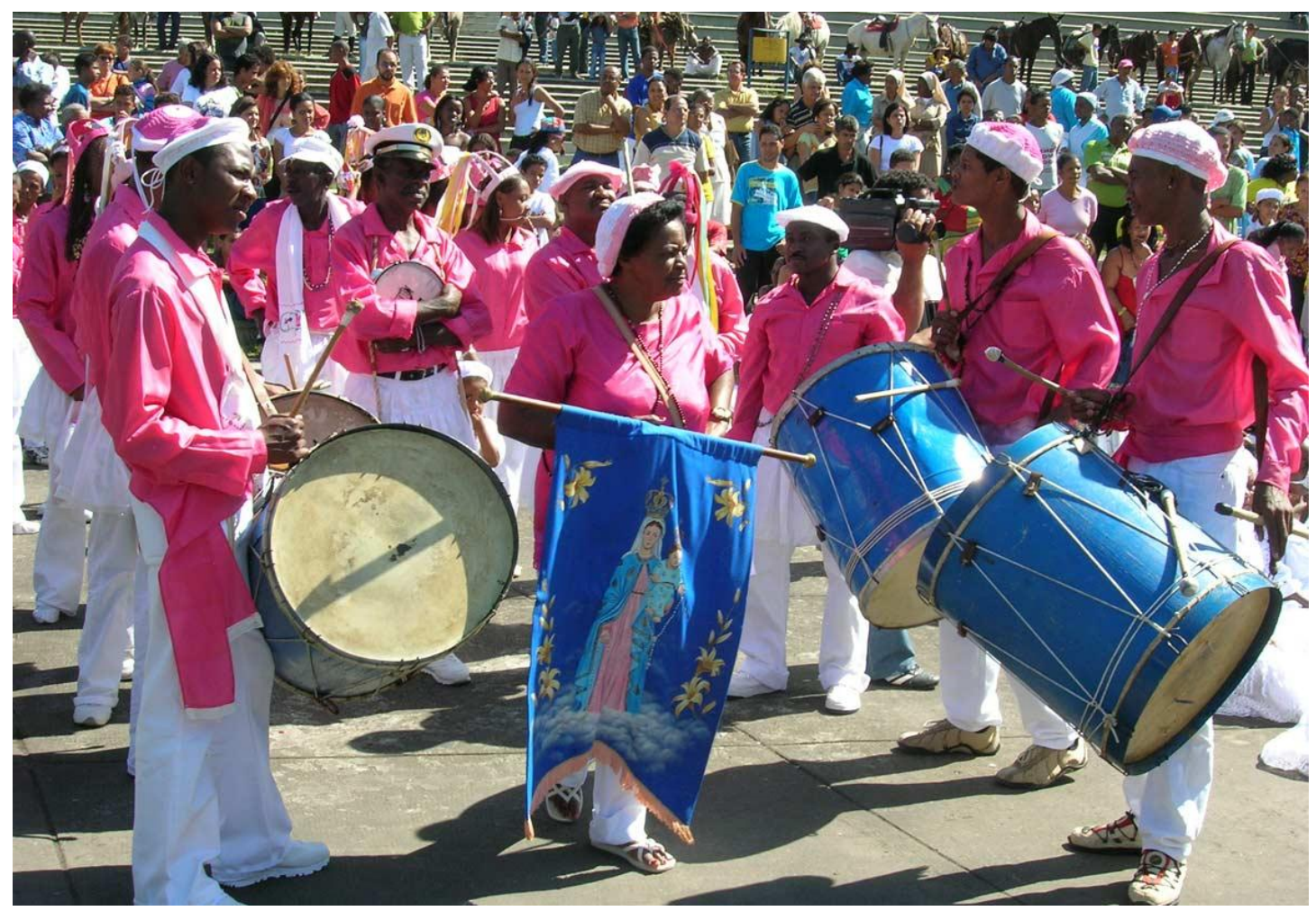

Figure 1. The Congo group belonging to the Arturos community preparing to play in the centre of the town of Contagem, Minas Gerais, $13^{\text {th }}$ May 2006.

Each community promotes a yearly Congado festival in honour of Our Lady of the Rosary. For between three and seven days devotees sing, play and dance in worship of Our Lady, other saints and their ancestors. Some brotherhoods also perform a shorter festival in May, lasting two days, to celebrate the end of slavery. Given that the groups spend several hours processing around a host community or town, frequently passing within earshot of each other, and that in some circumstances groups which meet on a road or path are expected to face each other and perform a ritual of mutual greeting; and given that the groups are frequently playing similar rhythms at similar tempi when they do so, we hypothesize that resisting entrainment is in practice rather difficult, and that on occasion unintentional entrainment is likely to occur. The participants' discourse, and the fact that groups often appear to avoid situations in which they would have to perform greetings, both offer support to this idea. The present paper, which is based on audiovisual recordings made at a Congado festival in the town of Contagem, Brazil in May 2006, analyses four occasions on which groups played in close proximity to one another, including one formal greeting, to see whether or not the groups mutually entrain. Two of the events involve groups from the same community; the other two occasions involve groups from different communities.

The analyses presented below take into account extant literature on entrainment as well as ethnographic research conducted with the participants. Rather than a series of controlled experiments intended to test specific hypotheses, the analyses explore the real-life data with both entrainment theory and ethnography in mind, in search of interpretations consistent with both perspectives. We have also brought these two approaches together where possible: for instance, both by asking the participants about phenomena we identified through the entrainment analyses, and by bringing detailed knowledge of the ritual and its musical repertoire to bear in the process of analysis (especially in Extract 4). Looking at the data from the perspective of entrainment theory we set out to characterise two groups as independent rhythmic systems (i.e. identifying the rhythmic patterns and their tempi) and the means by which these systems might have become coupled (principally, when auditory and/or visual information about one group's rhythm was available to the other). We would expect an interaction between the proximity of the two tempi and the coupling strength: the closer the two groups are in tempo, the weaker the coupling force 
necessary for the two groups to synchronise. In terms of how the coupling occurs, in a musical context auditory information is of course important. However, a number of studies have pointed to the role of visual information in unintentional interpersonal coupling (Richardson et al., 2005; Richardson et al., 2007; Schmidt \& O'Brien, 1997) and we have therefore also considered the likelihood that visual contact may have contributed to the instances of entrainment identified below.

\section{CONGADO: ETHNOGRAPHIC CONTEXT AND MUSICAL ELEMENTS}

The Congado festival where the recordings were made in May 2006 was promoted by the Black Community of Arturos, a family group named after its founder - Arthur Camilo Silvério - who was born around the end of slavery in Brazil, in the last quarter of the $19^{\text {th }}$ century. Arthur and his wife Carmelinda raised their children according to cultural values and knowledge inherited from his African ancestors, including the faith in Our Lady of the Rosary and the importance of his family's union and solidarity. Today there are around five hundred descendents, and approximately three hundred of them share a piece of land that Arthur had inherited from his father. There the group preserves and recreates several traditions linked to Brazilian black culture. The ceremonies of the Reign of Our Lady of the Rosary, widely known as Congado, are the most important such. Congado is the expression of their faith. Some of Arthur's sons and daughters are still living: they are the family's leaders and occupy the most important positions in the spiritual hierarchy.

During the rituals, the social structure of a Congado community includes the establishment of a royal court and of performative groups that conduct the rituals and protect the royalty. Kings and queens represent the honoured saints and African ancestral leaders. Arturos have three different kinds of group: a Congo, a Moçambique and a Candombe. These groups perform specific and complementary functions, which are established according to the hierarchical organization determined by a founding myth (Lucas, 2002a). Congo and Moçambique perform in the street and other public places. They are formed of Captains, who are spiritual leaders who normally conduct the singing, and of vassals, who include the dancers and players. Candombe is an indoor ritual that is performed by the leaders of the community and is restricted to community members. It is regarded as the foundation of the other groups and it is performed with vertical hand drums (played while standing) and shakers. The drums are said to allow the interaction between devotees and their ancestors, and are therefore sacred. Congo and Moçambique players carry cylindrical drums that are played with sticks and are said to represent Candombe's sacred drums.

Moçambique represents Candombe in the public spaces and their rhythmic characteristics echo Candombe's rhythm. The group performs their ritual acts with two rhythmic patterns, which are normally played in moderate or slow tempo because Moçambique guides and conducts the royalty that follows them in processions (Figure 2).

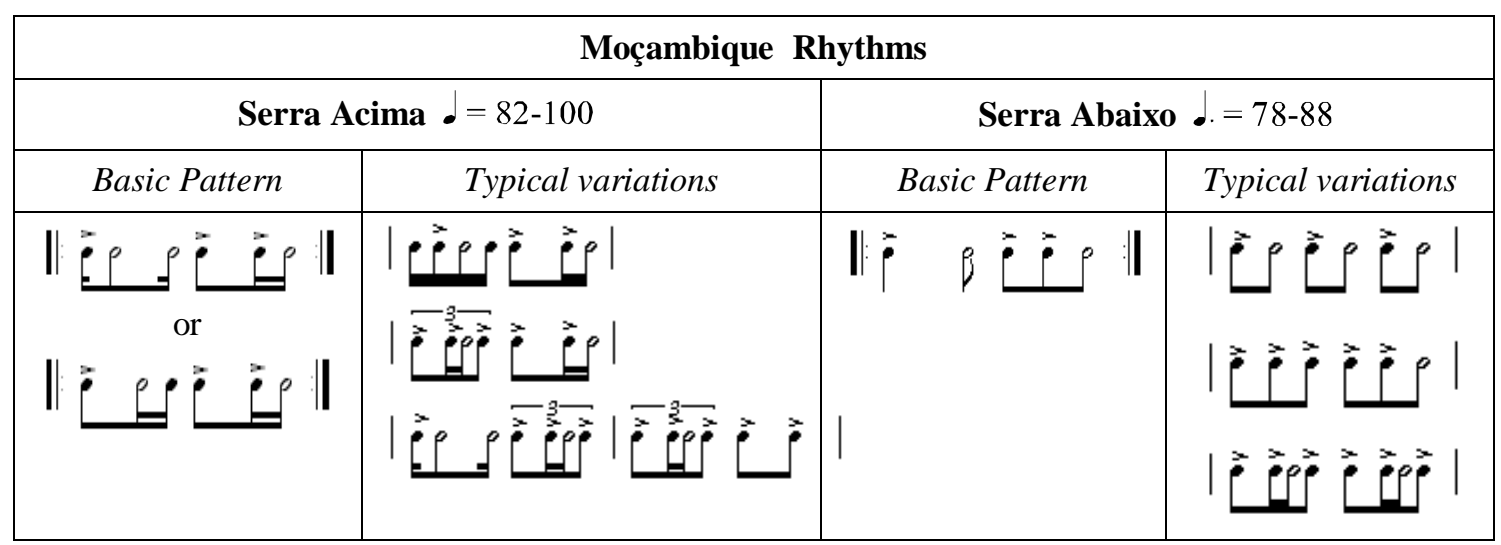

Figure 2. Approximate transcription of Moçambique's rhythmic patterns. The white note heads represent weaker strokes made by the non-dominant hand, which rests on the drum.

Congo leads the processions, cleaning the way of evil energies and protecting Moçambique and the royalty behind. This function is accomplished by playing and dancing to fast rhythms that are submitted to frequent variations, which create a protective shield of sound and movement. The group plays four rhythmic patterns that provide them with a wide range of tempo possibilities. The most used are the slowest (Marcha Grave) and the fastest (Dobrado) ones (Figure 3). 


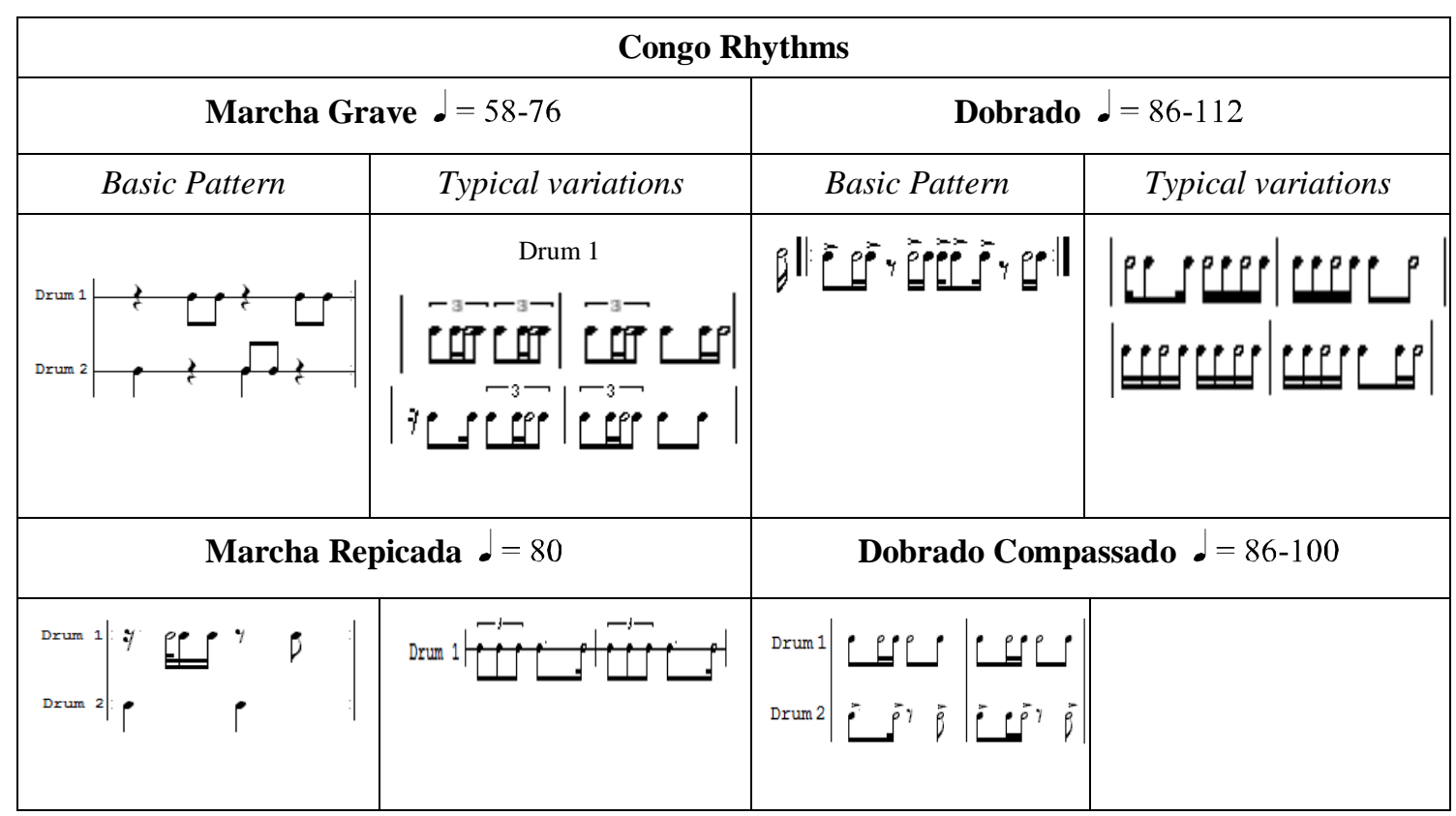

Figure 3. Approximate transcription of Congo's main rhythmic patterns. The white notes represent weaker strokes made by the non-dominant hand, which rests on the drum.

Among the celebrations commemorating the end of slavery, Arturos' May Festival is the most important one in Minas Gerais. It lasts two days. Saturday rites are restricted to Arturos' Congo and Moçambique and are carried out after sunset. These groups, either together or separately, raise several poles - with flags picturing their patron saints - in strategic places both within the community space and also in important sites in the neighbourhood, such as the Church of Our Lady of the Rosary in the town of Contagem.

Sunday starts with a celebration for the ancestors at dawn, conducted solely by Moçambique. The group processes along the streets towards the Church of Our Lady of the Rosary and returns to the community. After breakfast both groups get dressed in their uniforms and go back to the Church to take part in a 'Congo Mass' conducted by the local priest, including both groups' music. There they meet many other invited Congado groups from other communities in Minas Gerais, who also watch the Mass. When the celebration finishes, all these groups - from around fifteen up to twenty in total - process back to the community while dancing and playing different songs simultaneously. Here, the groups will take turns for lunch. While some groups are having their meals, others perform in different parts of the community carrying out different obligations, such as helping devotees to pay promises,${ }^{[1]}$ honouring the saints at the altar of the community's chapel, and saluting Arturos' leaders, especially Arthur's sons and daughters, in front of their houses. All the groups - hosts and visitors - play different roles in the rituals. Therefore they sing and play different songs and rhythms, all at the same time. Through these simultaneous performances each one also expresses its identity as a Congado community. Late in the afternoon there is a large procession towards the Church, where they carry images of honoured saints (Our Lady of the Rosary, Saint Benedict the Black, Saint Iphigenia, among others) to take to the Church. Back in the community, the groups lower the flags and carry out the final acts of the festival in the chapel.

\section{METHOD}

The study presented in this paper is based on the analysis of video footage filmed during the festival hosted by the Arturos community on Saturday 13th and Sunday 14th May 2006. The main purpose of the recordings was to document occasions on which two Congado groups either meet and exchange ritual greetings or come into close proximity with each other. The case studies investigated below were selected from both days of the Congado ritual.

The audiovisual recordings were made by a team of six people ${ }^{[2]}$ divided into three filming units, each using one video camera (Sony PD-170) shooting in DVCAM format. Audio was recorded in 48 $\mathrm{kHz} / 16$ bit format. For units 1 and 2, four radio microphones (Sennheiser ew100-ENG G2) were employed, 
attached to two of the main drums of each of the Congo and Moçambique groups of the Arturos community. The audio signals from the radio microphones were fed to the cameras - from the Congo to camera 1, and from the Moçambique to camera 2 - via two portable field mixers (Sound Devices Mix-Pre and SQN 4S), where they were mixed with signals from two rifle microphones mounted on boom poles (one of these rifle microphones was a Sennheiser K6-ME66, the other - which gave inferior results - a cheaper generic model). The rifle microphones allowed each unit to record all of the singers and percussionists of each group. The third unit recorded audio through the camera's own external microphone and provided an overall record of the soundscape of the ritual, often including two groups in the shot or panning between two or more groups.

On the Saturday night, when Congado is only performed by the two Arturos' groups, this set up allowed units 1 and 2 to focus respectively on the Congo and on the Moçambique. On the Sunday, when Congado groups from other communities join the festival, a much higher degree of flexibility in recording was required: in fact, as the different groups moved freely around the Arturos' community and the town of Contagem (covering an area of several hundred square meters), it was not possible to predict which groups would meet, where or when, and therefore to plan the filming in advance. However, units 1 and 2 - who were mostly following their respective Arturos' group - could temporarily disable the radio microphones' signals and limit the audio input to the rifle microphone only, and in this way record a group other than the Arturos Congo or Moçambique. Unit 3 maintained the same settings and tasks as the previous day.

DVD copies of all of the tapes were made with embedded time code, and the first stage of analysis involved logging the events on each tape in Excel spreadsheets. Working from these logs we selected for analysis nine occasions on which two groups had played in close proximity. All of the video footage was captured to Avid Media Composer video editing software, and the extracts relating to these occasions were identified for preliminary editing.

Accurate synchronisation of the different shots was a lengthy process. We began by identifying matching sections of the three shots using the camera time code, which had been set manually to approximately the same time. Audio tracks were then exported and accurately synchronised in Audition, using a form of triangulation between the three cameras: we matched the soundtracks of cameras 1 and 3 at one point in an extract, and then synchronised cameras 2 and 3 at a different point in the same extract. This process allows us to be confident of the synchrony between cameras 1 and 2 when the respective units were focusing on different groups. Re-importing the adjusted audio tracks into Avid allowed us to then synchronise the video tracks to within one frame $(0.04$ secs $)$. On several occasions disturbances such as tape changes resulted in gaps in the timing data, which are visible on the charts below. In these cases the different sections of extant recordings had to be synchronised separately.

Timing data were derived from the audio tracks by tapping while listening to the audio tracks (using Transcribe! software): the measure is therefore of perceived tempo rather than of drum onsets, which were impossible to extract from these recordings because each track contains the sounds of many drums playing simultaneously. In the first instance we tapped to a regular beat in each case, usually that indicated by $\downarrow$ or $\downarrow$. in Figure 3. At a later stage in the analysis we tapped out the three main drum beats of the extracts employing the Dobrado rhythm (see Figure 31 below). The tempo graphs below are all based on the former. All of the extracts were tapped by Lucas, who has by far the greatest familiarity with the repertoire, and these data were used for the analyses. All extracts were, however, tapped more than once to check the reliability of the data. To give one example, in Extract 4 we compared the first tapping runs of Clayton and Lucas. The average difference between the individual taps was 20 msecs, with over $85 \%$ of corresponding taps falling within $40 \mathrm{msecs}$ (the periodicity of the beat tapped was generally over 600 msecs). This suggests that the data give a reliable indication both of tempo trends and of the relative placement of the beats between the groups. In order to have a robust measure of tempo that is less affected by short-term fluctuations and outliers we used moving averages (over 7 or 9 data points) in order to test for correlations between the tempo trends of two groups. Some of the variability in the relative phase data will be due to micro-timing errors in the tapping: our assumption here is that such random variation will not significantly affect the calculations of mean phase angles which form the bulk of our analyses below (although they could lead to some underestimation of the strength of coupling between the two rhythms).

Having generated and checked the timing data, these were analysed using established methods for determining the degree of synchrony - and hence entrainment - between two rhythmic processes (see Clayton, 2007; Clayton, Sager \& Will, 2005). First, the time series extracted in Transcribe! were exported into Excel. From this data plots of tempo vs time were generated in order to give a visual impression of how close the groups were in tempo at each point in the extract. Then, the relative phase of each pair of time series was calculated in Excel. ${ }^{[3]}$ Two graphical representations were generated from this data: one a 
circular plot of the distribution of relative phase angles (in Oriana), the other a linear plot of relative phase against time (in Excel). The linear plot of relative phase against time indicates how this relationship changes over the course of the extract. If the phase relationship between the two groups stabilises for just a portion of the extract, this phenomenon is apparent from this plot: in this case the data points appear to stabilise or oscillate around a horizontal line representing a particular phase angle (otherwise the relative phase tends to drift continuously, the data points forming a series of diagonal lines). Where this was observed, circular plots were then made of these portions only, in order to analyse the phase relationships in more detail. Summary statistics were also calculated in Oriana. The two principal measures are the angle of the mean vector $\mu$ (which provides an indication of the phase attractor in entrained systems) and its length $r$ (which indicates the strength of coupling). ${ }^{[4]}$ Graphical representations were therefore used as a heuristic device, and circular statistics for detailed analysis of inter-group entrainment.

We also revisited the tempo data relating to periods when two groups appeared to entrain. The trends lines (calculated as moving averages) were inspected visually, and the averaged time series were also analysed in order to ascertain whether two groups' tempo trends were correlated. Where the tempo trend lines are correlated, this provides further corroboration of an entrainment hypothesis. This is because synchrony does not in itself prove that two rhythmic processes are entrained: this synchrony needs to reassert itself following a perturbation. A correlation between two tempo trends can be regarded as a series of perturbations and reactions: in the simplest case, one group spontaneously speeds up and the other responds. Correlated averaged time series therefore provide strong evidence for entrainment.

In the following sections we focus on the entrainment analyses themselves, but also provide enough contextual description to enable the reader to understand what was going on in each case. From the nine events selected for analysis, the four examples presented in this paper were chosen as providing sufficient information to describe inter-group entrainment, and its avoidance, in this Congado festival.

\section{ANALYSIS}

\section{Extract 1. Saturday evening: Two groups belonging to the Arturos Community pass each other}

Recorded on 13th May 2006 from 7.37 pm; duration 6 min $19 \sec (379$ secs)

This extract, recorded early on the first evening, features the physical crossing of two groups belonging to the Arturos community. At the start of the extract the Arturos Congo group (AC) completes its ritual greeting at the house of community matriarchs Dona Tita (full name Izaíra Maria da Silva) and Dona Induca (full name Maria do Rosário da Silva), Arthur's daughters, which lies at the bottom of an inclined path. AC then performs a circular manoeuvre known as a "half moon" ${ }^{[5]}$ and moves off uphill towards the central courtyard and the community's chapel. Meanwhile, the Arturos Moçambique group (AM) leaves the chapel and processes downhill towards the same house. The two Captains pass each other at 291 secs, at which point the two rows of AC separate and allow AM to pass between them on their way downhill (see summary diagram, Figure 4). This can only occur with two groups belonging to the same community: if the groups came from different communities they would have passed by the side of each other. The two groups, as always, are singing their own songs - which relate to the task or activity they are carrying out at the time - to the accompaniment of their own distinctive rhythmic patterns.

This extract was chosen as an opportunity to check for evidence of entrainment as the two groups pass each other. All three filming units captured parts of this event: unit 1 following AC, unit 2 following $\mathrm{AM}$, and unit 3 positioned strategically at the meeting point. Although Cameras 2 and 3 did not capture the whole of the time period captured on Camera 1, enough data was captured to enable analysis of the event.

While performing the greeting ritual, AC was playing Marcha Repicada, with its moderate tempo of around $80 \mathrm{bpm}$. When the greeting ended, this group changed to the faster Dobrado rhythm in order to leave and walk uphill. The tempo data for AC shows this abrupt acceleration to about $100 \mathrm{bpm}$. Meanwhile, AM had started its Serra Acima rhythm at c. 92 bpm, faster than AC's Marcha Repicada (80$86 \mathrm{bpm}$ ), gradually accelerating to the tempo of AC's Dobrado rhythm (c. $100 \mathrm{bpm}$ ) over a period of about $2 \frac{1}{2}$ mins (roughly 80-230 secs, see Figure 5). 


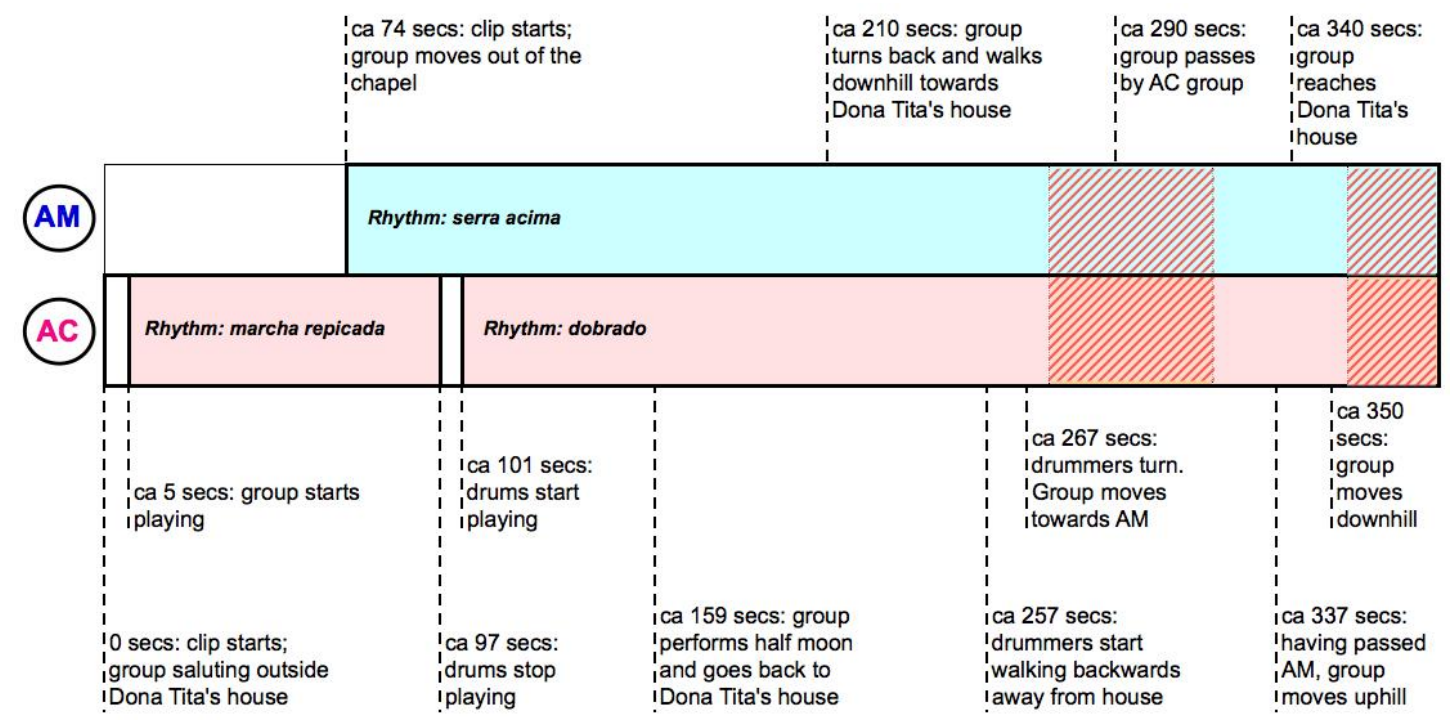

Figure 4. Summary diagram of the events of Extract 1, in which the two Arturos groups passed each other. Red diagonal shading indicates the periods when the two groups became mutually entrained, as will be demonstrated below (cf. Figure 6).

The plot of relative phase vs time for Extract 1 (see Figure 6) shows no evidence of stabilisation in the phase relationship until about $271 \mathrm{secs}$, at which point the series appears to settle around $0^{\circ}$. This continues until approximately 319 secs, at which point the relative phase drifts to just over $120^{\circ}$, before appearing to stabilise again later on (c. 353 secs).

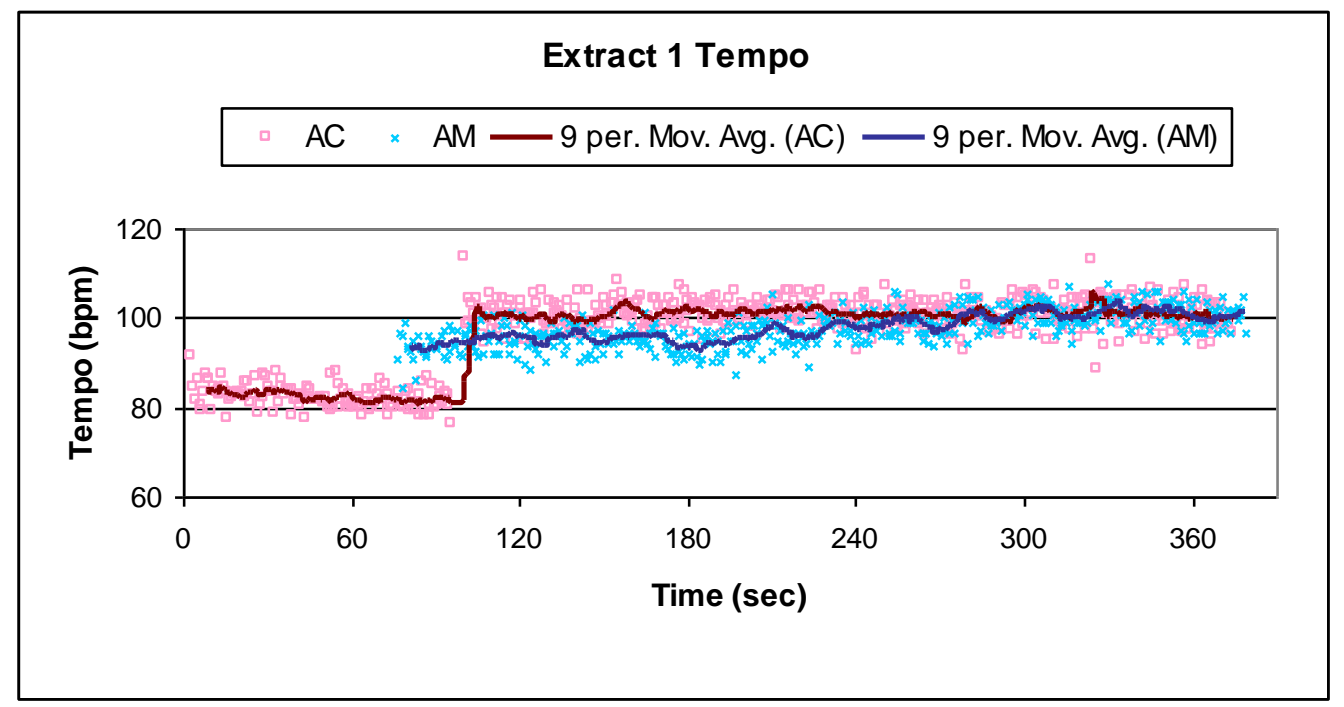

Figure 5. Tempo chart for AC (Arturos' Congado) and AM (Arturos' Moçambique) groups, Extract 1. '9 per. Mov. Ave' indicates the trendline based on a 9 point moving average of the tempo data. 


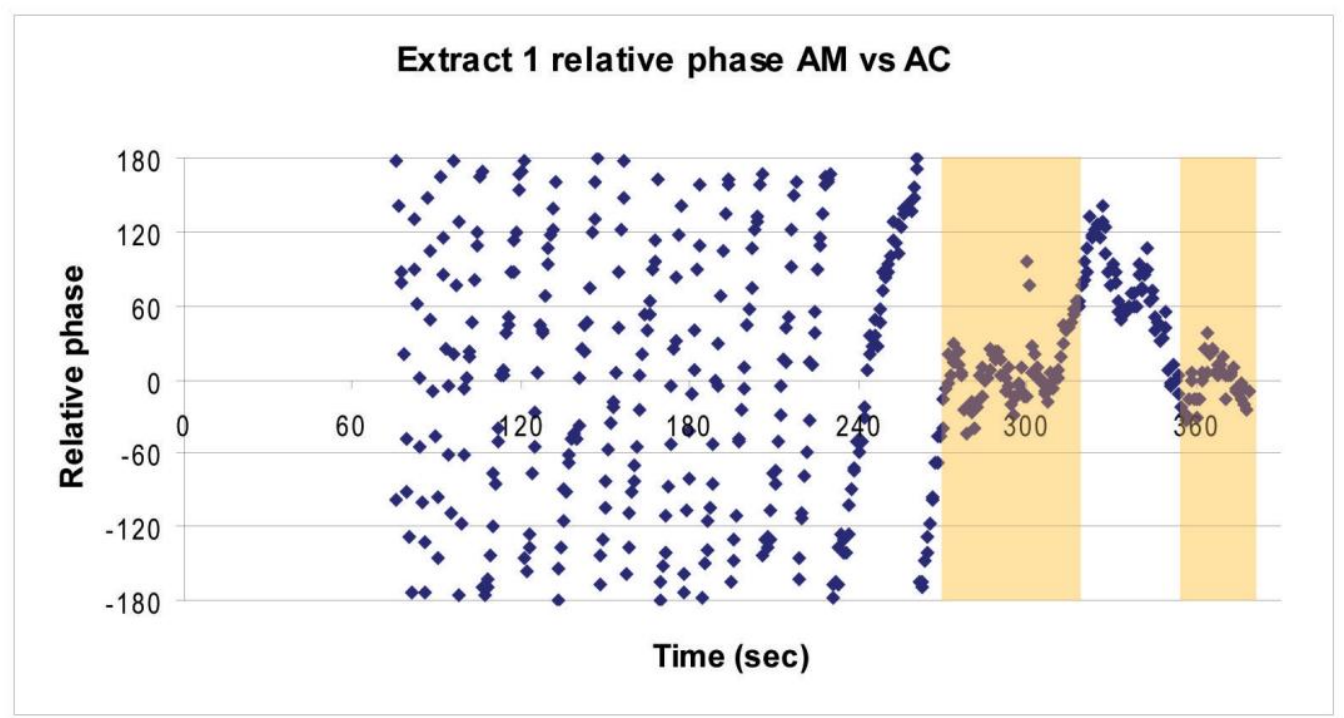

Figure 6. Relative phase plot of AM vs AC for Extract 1. Shading indicates periods of phase stabilisation, which were identified visually on the chart in the first instance and subsequently investigated statistically (cf. Figure 4).

The tempo chart for the period from 270 secs to the end of the clip shows how the tempo trends move together from about $270 \mathrm{sec}$ (see Figure 7), apart from a short time around 320-330 secs when AC accelerates. This occurs once the groups have passed each other and are moving off in different directions. Both charts suggest an extensive period of entrainment which is temporarily disturbed (there is a tempo disturbance for 10 seconds and a phase disturbance for 34 seconds). The two periods of apparent stabilisation (271-319 and 353 -379 secs) are now analysed in detail.

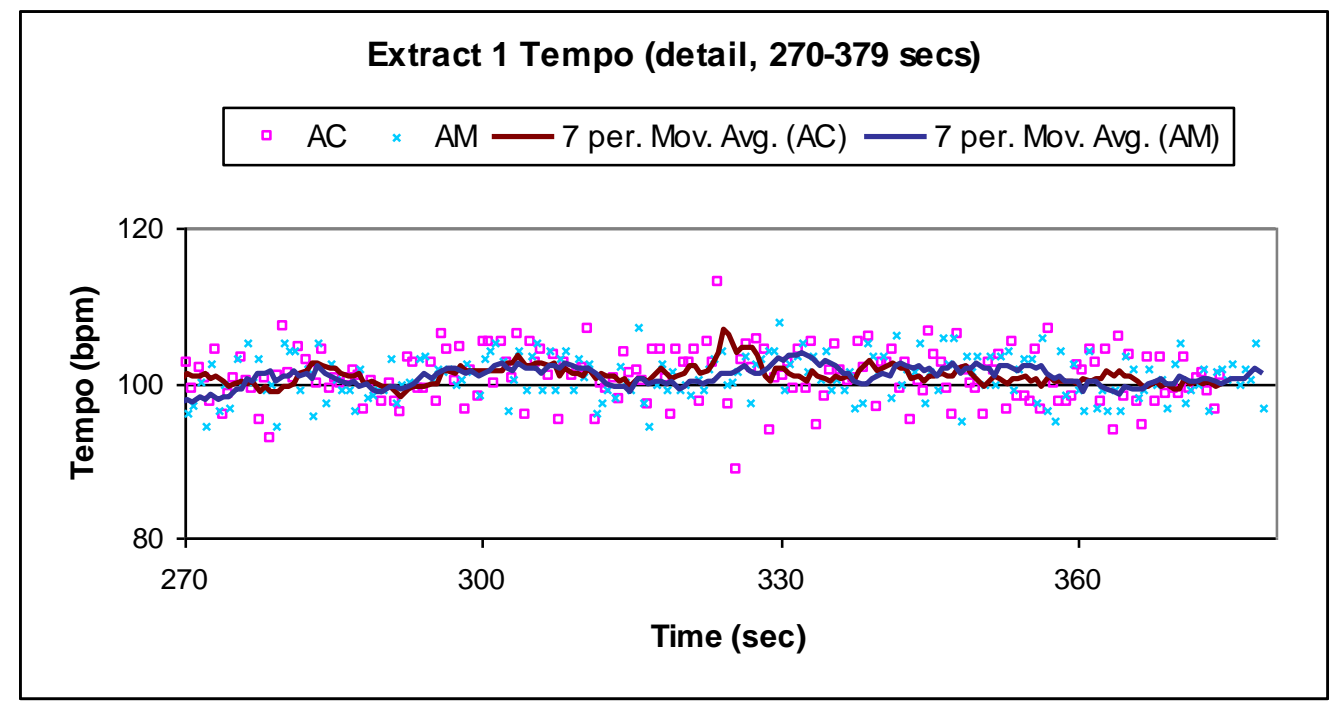

Figure 7. Tempo chart for Extract 1, 270-379 secs only.

\section{EXTRACT 1, FIRST PERIOD OF STABILISATION (271-319 SECS)}

The circular plot and statistical analysis show clearly that for the period between 271 and 319 secs the groups are closely synchronised, with a mean vector $\mu=359.6^{\circ}$ (i.e. almost exactly $0^{\circ}$ ), $r=0.963$ (see Figure 8 for the phase plot and Table 1 for summary statistics). On first inspection it is clear that this period relates to the crossing of the two groups (see Figure 4). More detailed analysis of the video, however, shows that the groups actually start to cross each other at 291 secs, 20 secs after they had become 
entrained. The phase-locking corresponds to the point at which both groups have started moving towards each other and have made visual contact (the AC drummers turn after performing an "half moon", and start moving towards AM at 267 secs). They would have been in auditory contact for some time before this, although it is impossible to determine exactly how long from the recordings.

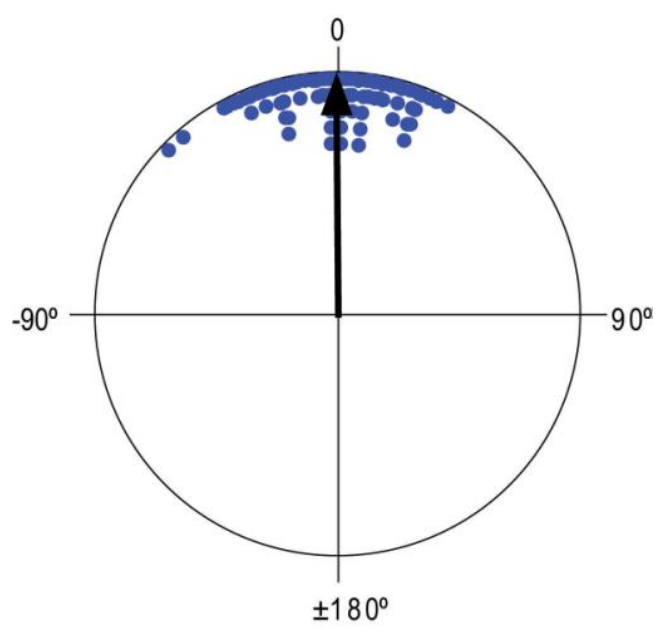

Figure 8. Circular plot of phase angles for Extract 1, 271-319 secs only. The mean vector is indicated by the arrow. ${ }^{[6]}$

\begin{tabular}{|l|l|}
\hline Number of Observations & 82 \\
\hline Mean Vector $(\mu)$ & $359.563^{\circ}$ \\
\hline Length of Mean Vector $(r)$ & 0.963 \\
\hline Circular Standard Deviation & $15.708^{\circ}$ \\
\hline Rayleigh Test $(Z)$ & 76.063 \\
\hline Rayleigh Test $(\mathrm{p})$ & $<1 \mathrm{E}-12$ \\
\hline
\end{tabular}

Table 1. Statistical analysis for Extract 1, 271-319 secs only.

\section{EXTRACT 1, SECOND PERIOD OF STABILISATION (353-379 SECS)}

Having completed the passing manoeuvre the groups appear to lose their mutual entrainment as the relative phase drifts for some 30 seconds (319-353 secs), reaching a little over $120^{\circ}$. From 353 secs to the end of the extract at 379 secs, however, the relative phase plot suggests that they may become phase locked once again. The circular statistics confirm that this is the case, but that the synchronization is slightly out of phase $\left(\mu=349^{\circ}\right)$ and the length of the mean vector is significantly less at 0.900 , indicating a looser entrainment here than in the first period of stabilisation (see Figure 9 and Table 2). The video of the event shows that the AC group, having reached the top of the hill, again turns to face the AM group at 350 secs: thus, once again, entrainment seems to correlate with visual contact (see Figure 4). 


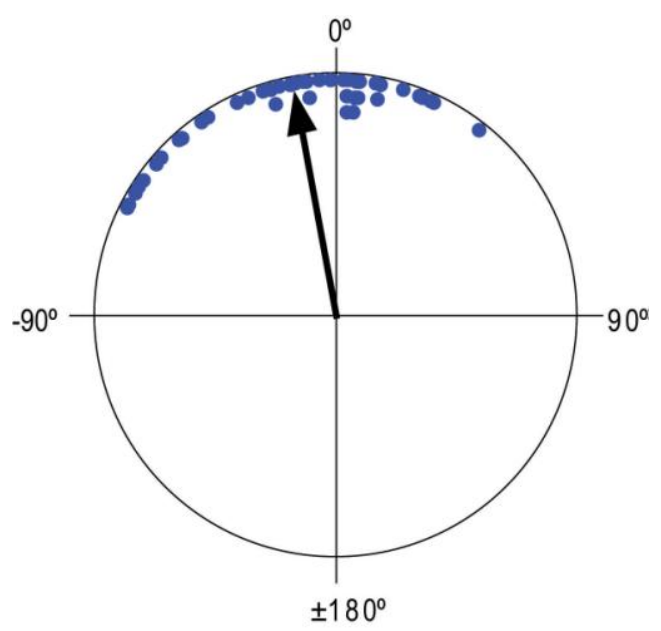

Figure 9. Circular plot of phase angles for Extract 1, 353-379 secs only.

\begin{tabular}{|l|l|}
\hline Number of Observations & 43 \\
\hline Mean Vector $(\mu)$ & $349.138^{\circ}$ \\
\hline Length of Mean Vector $(r)$ & 0.900 \\
\hline Circular Standard Deviation & $26.271^{\circ}$ \\
\hline Rayleigh Test $(\mathrm{Z})$ & 34.847 \\
\hline Rayleigh Test $(\mathrm{p})$ & $<1 \mathrm{E}-12$ \\
\hline
\end{tabular}

Table 2. Statistical analysis for Extract 1, 353-379 secs only.

\section{Extract 2. Saturday evening: Two groups belonging to the Arturos Community play together as a flag is raised}

Recorded on 13th May 2006 from 11.13 pm; duration c.19 min

This second extract features the AC and AM groups, who having returned to their own community after progressing around the town of Contagem on the first evening, are back in the courtyard outside their own chapel. This extract starts with AC entering the chapel briefly, while AM is approaching, and ends with AC going into the chapel again. In the course of the extract AM raises a flag in the centre of the courtyard while AC stands nearby playing a different song in support. This forms a powerful climax to the evening's events. The extract was chosen to enable a study of entrainment effects while the two groups play in close proximity for a sustained period: it seemed clear at the time that the two groups had entrained and played in synchrony for a time. This was the only instance during the whole festival in which it seemed clear to the authors that two groups had entrained and played in synchrony for a time (see Figure 10).

Again, we present first a tempo chart to provide an overview of the event (see Figure 11). This shows that the AC group decelerates slightly from about $104 \mathrm{bpm}$ to $98 \mathrm{bpm}$ (playing the Dobrado rhythm), before switching to a slow tempo Marcha Grave rhythm, c. 64 bpm, from about 895 secs. AM starts the extract at a similar tempo to AC (c. $100 \mathrm{bpm}$ ), then the remainder of the clip shows two ascending contours. This corresponds to two complete songs, which both start at about $88 \mathrm{bpm}$ and then gradually accelerate. ${ }^{[7]}$ The two groups play at roughly the same tempo between about 700-900 secs, after which AM accelerates to c. $108 \mathrm{bpm}$. The tempo chart appears to show a 'flattening' of the AM's otherwise constant acceleration during this period. 


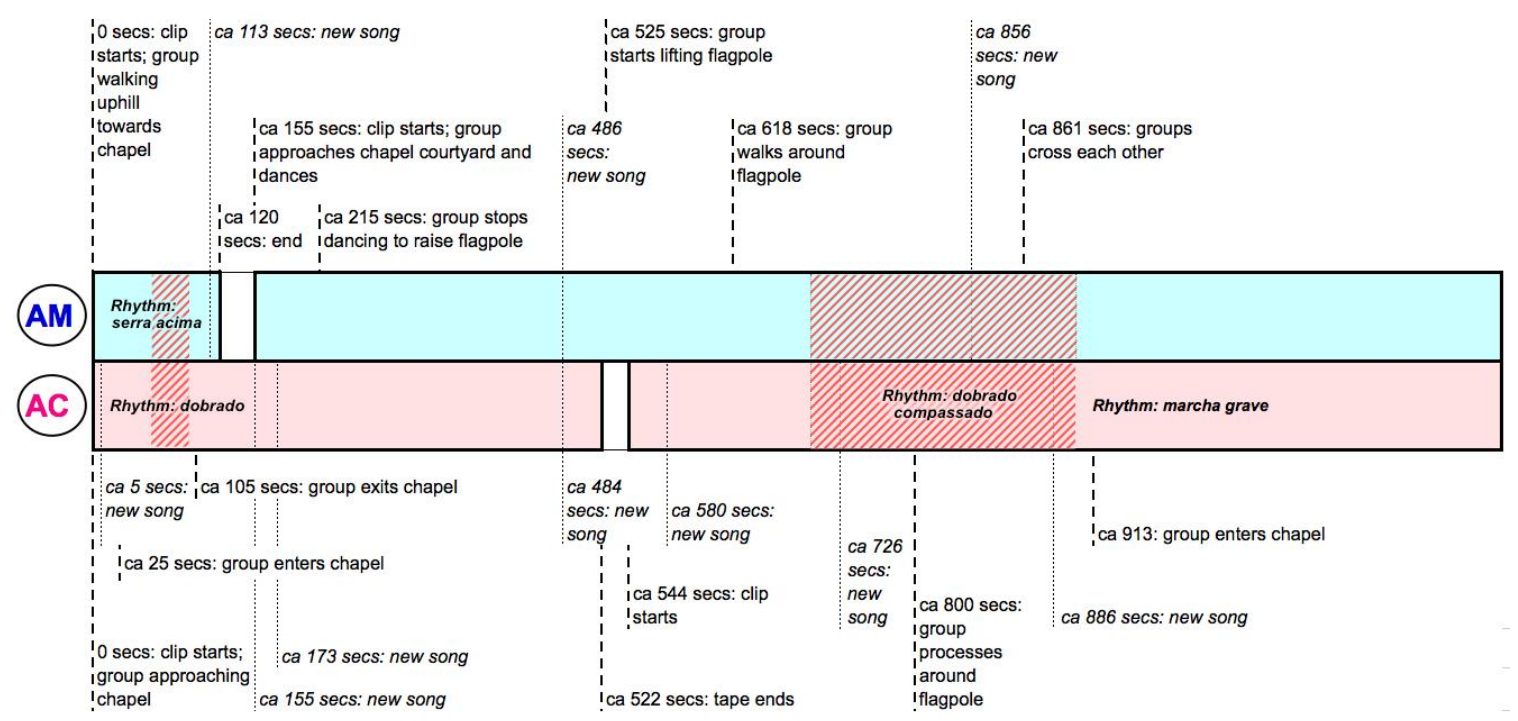

Figure 10. Summary diagram of the events of Extract 2. Red diagonal shading indicates the periods when the two groups became mutually entrained, as will be demonstrated below.

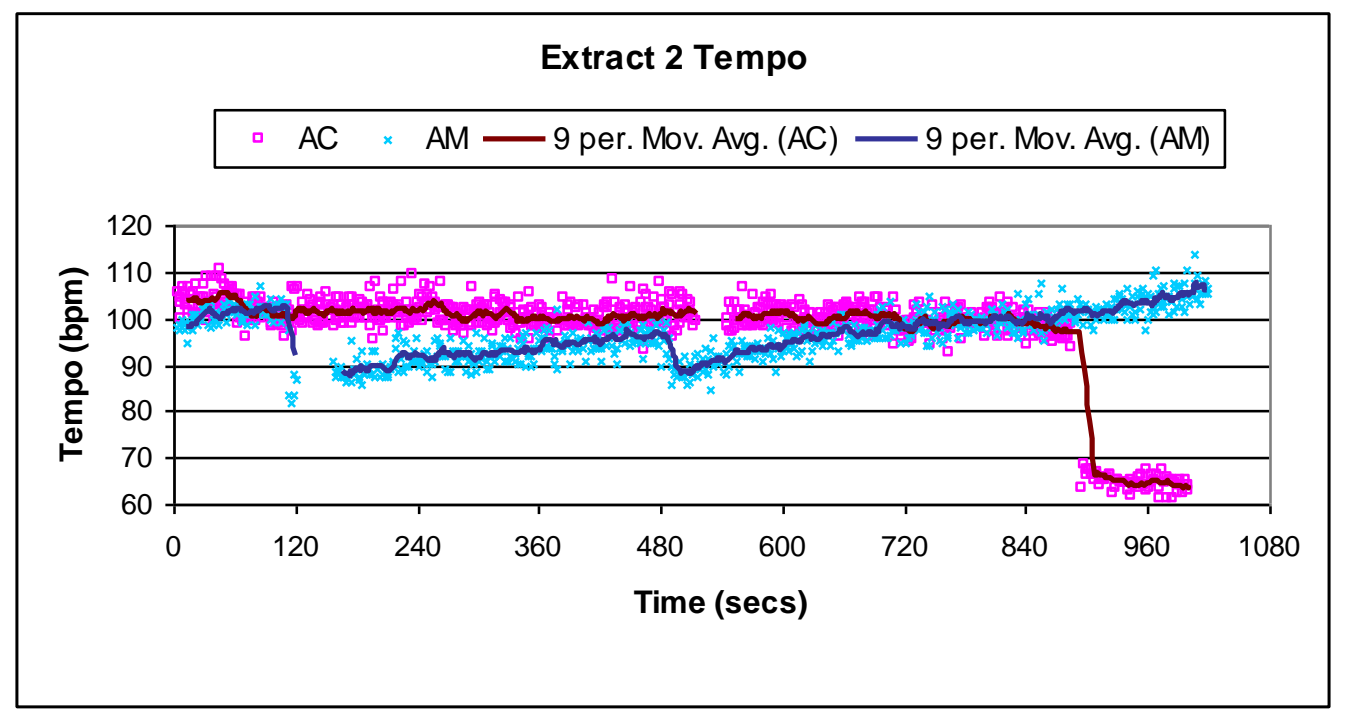

Figure 11. Tempo chart for Extract 2.

Figure 12 below shows the plot of relative phase against time. For most of the extract, this plot suggests that the phase has not stabilised. There may be a brief stabilisation within the first 100 secs or so, and there is a clear and sustained period of stabilisation between about 720 and 840 secs. Again, these two periods will now be analysed separately. 


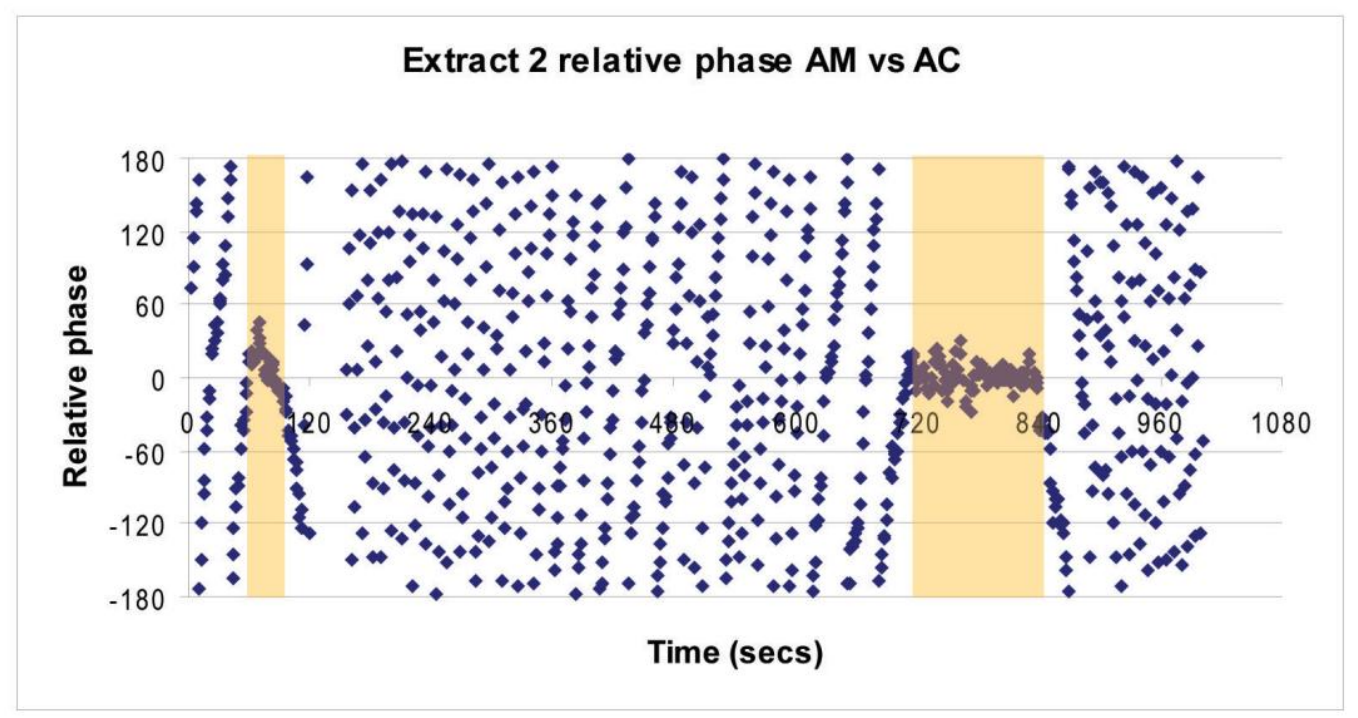

Figure 12. Relative phase plot for AM vs AC in Extract 2. Shading indicates periods of phase stabilisation.

\section{EXTRACT 2, FIRST PERIOD OF STABILISATION (58-95 SECS)}

The relative phase plot remains around $0^{\circ}$ between about 58 and 95 secs: analysis of this period suggests a short term synchronization, with $\mu=8.294^{\circ}$ and $r=0.962$ (see Figures 13 and 14; Table 3 for summary statistics). This corresponds to a time at which AM is accelerating and AC decelerating, in other words at which the two groups' tempi cross. We would expect, therefore, that even without entrainment the relative phase plot would change direction, making an arch shape on the plot, which it does: if the two rhythms become entrained, the apex of the arch would be expected to flatten as the relative phase stabilises. Visual evidence of the latter is weak (Figure 13), although the chart is consistent with the hypothesis that the groups mutually entrain for a short period when their tempos almost match and their relative phase reaches $0^{\circ}$. The tempo chart for this period (Figure 15) seems, moreover, to indicate that the two tempo curves covary between about 75 and 95 secs. In fact, comparing the two series of tempo data (using 5-point moving averages to reduce random fluctuations), the Pearson correlation coefficient is 0.600 ( $p<0.05$ ); a similar test on the periods 55-75 secs and 75-95 secs did not yield significant correlations. It seems, therefore, that as the tempi of the two groups cross they briefly become entrained in phase with each other.

This apparent entrainment is hard to account for as it occurred while AC were performing inside the chapel and AM were outside in the courtyard (AC entered the chapel at 57 secs and left at 105 secs). The noise of the group playing inside the small confined space was very loud and the likelihood that AC could have attended to the sound of AM is very small; the possibility that AM could hear the sound of AC being directed out of the door of the chapel is somewhat higher. Given that one group was playing inside the chapel and the other outside, moreover, visual contact would have been extremely limited in this case. The most likely explanation is therefore that AM briefly became entrained to AC when they paid attention to the sound of the latter, at a time when the tempi of the two groups happened to be very close. 


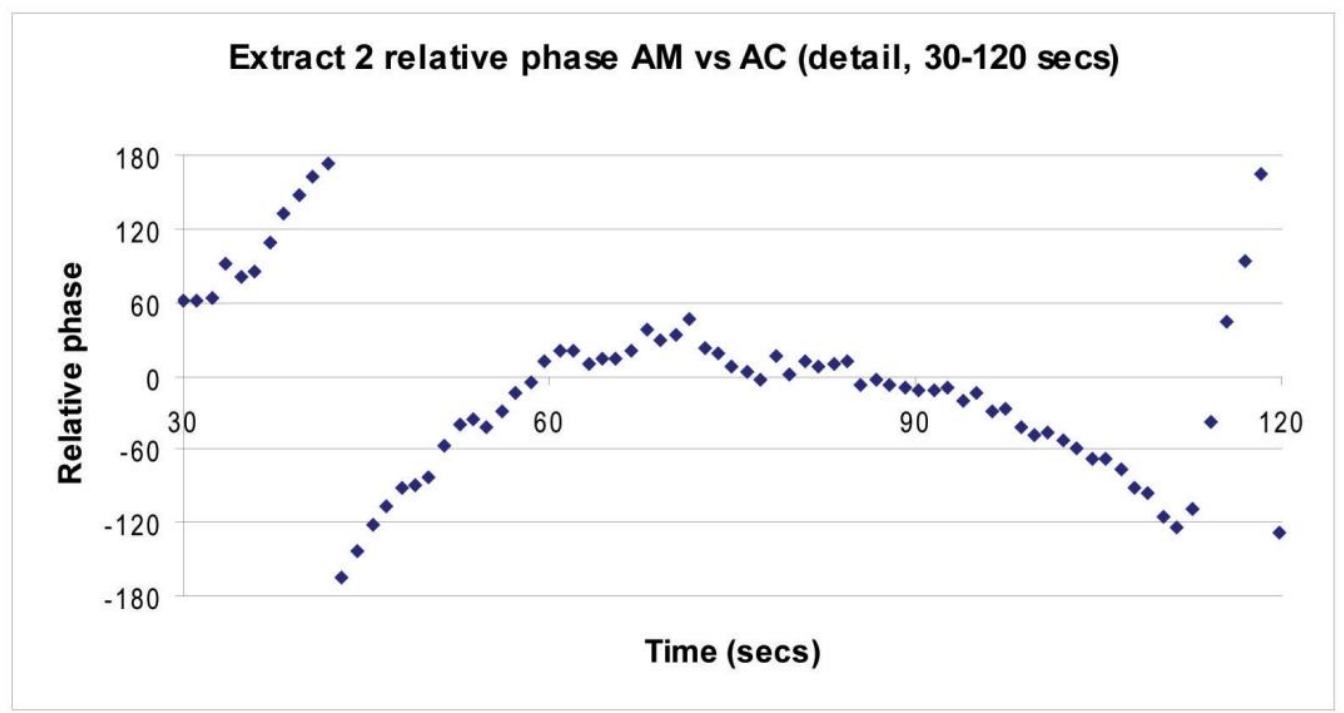

Figure 13. Relative phase plot for AM vs AC in Extract 2, 30-120 secs only.

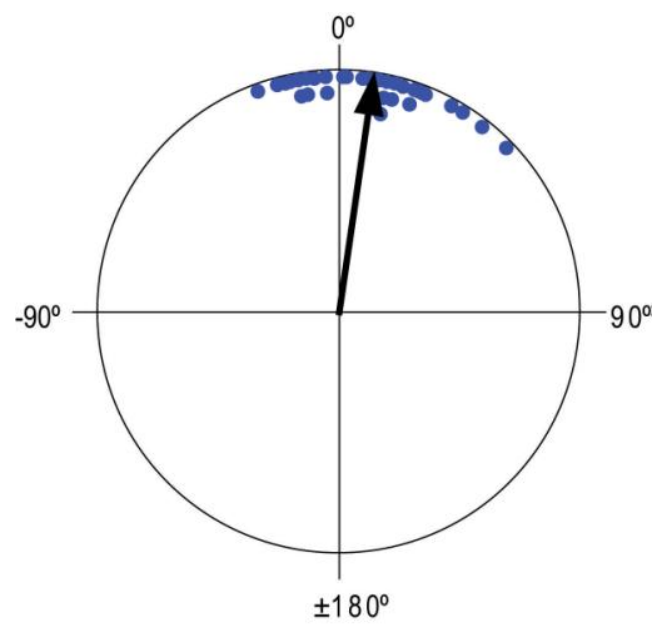

Figure 14. Circular plot of phase angles for Extract 2, 58-95 secs only.

\begin{tabular}{|l|l|}
\hline Number of Observations & 32 \\
\hline Mean Vector $(\mu)$ & $8.294^{\circ}$ \\
\hline Length of Mean Vector $(r)$ & 0.962 \\
\hline Circular Standard Deviation & $15.885^{\circ}$ \\
\hline Rayleigh Test $(\mathrm{Z})$ & 29.632 \\
\hline Rayleigh Test $(\mathrm{p})$ & $1.60 \mathrm{E}-12$ \\
\hline
\end{tabular}

Table 3. Statistical analysis for Extract 2, 58-95 secs only. 


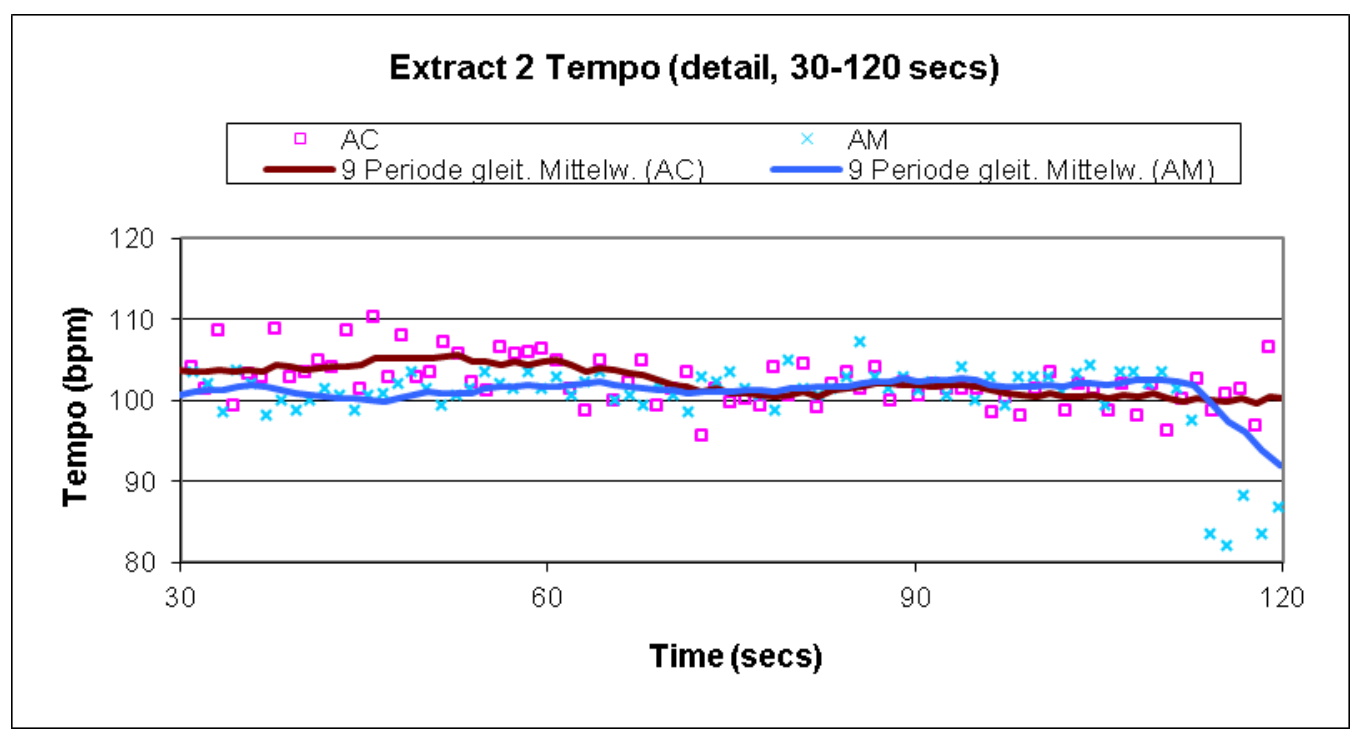

Figure 15. Tempo chart for Extract 2, 30-120 secs only, with moving averages.

\section{EXTRACT 2, SECOND PERIOD OF STABILISATION (718-840 SECS)}

The phase plots and circular statistics for this period (see Figures 16 and 17 and Table 4) show a mean phase angle $\mu=0.624^{\circ}$ and vector length $r=0.984$, confirming the close in-phase synchrony of the two groups for a period of about two minutes. The trend lines for the tempo during this period (see Figure 18) show that they co-vary between about 720 and 840 secs. The Pearson correlation coefficient (using 5-pt moving averages) is $0.562(\mathrm{p}<0.01)$.

This example highlights the mutual impact of the two groups' rhythms, while they remain playing in close proximity with their attention fully directed to the accomplishment of important ritual acts. Although AC and AM have different functions, which they perform by means of distinct songs and rhythms, they both belong to the same community. Therefore, they do not direct their attention towards avoiding entrainment, since they do not need to express their unique identities and origins through different tempi. Jorge Antônio dos Santos, AM Captain who was conducting the singing, was surprised when he saw the recordings and realized that both groups were synchronized immediately after the flag pole was raised. For him it is an unexplainable and very meaningful phenomenon that expresses the community's union around a shared goal. According to Jorge, synchronization meant that although they were doing different things, somehow they all remained linked one to the other. ${ }^{[8]}$

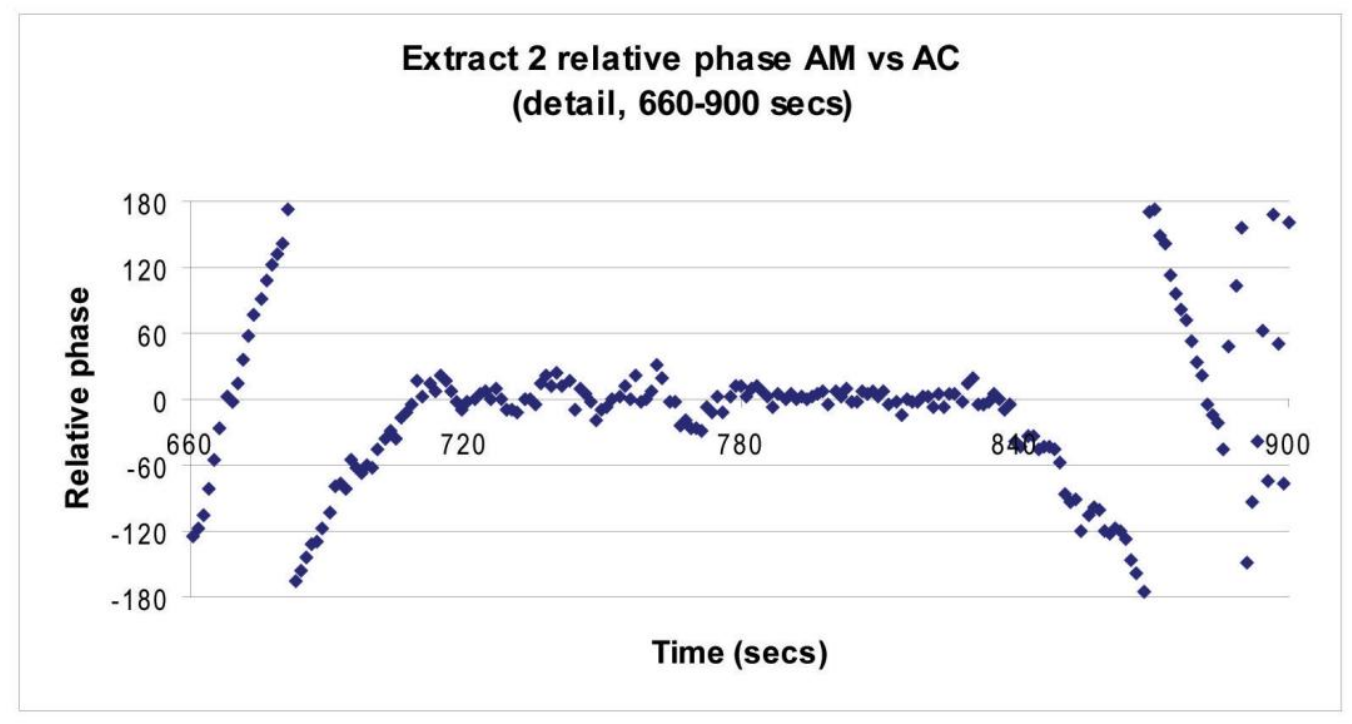

Figure 16. Relative phase plot for AM vs AC in Extract 2, 660-900 secs only. 


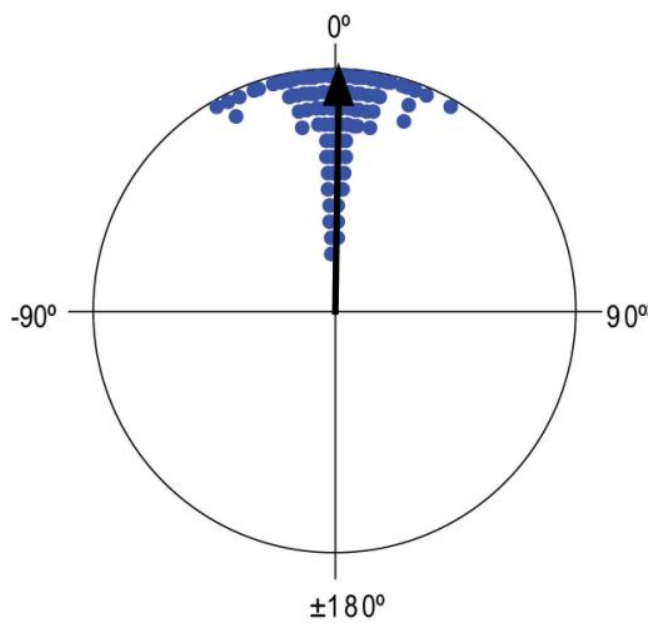

Figure 17. Circular plot of phase angles for Extract 2, 718-840 secs only.

\begin{tabular}{|l|l|}
\hline Number of Observations & 101 \\
\hline Mean Vector $(\mu)$ & $0.624^{\circ}$ \\
\hline Length of Mean Vector $(r)$ & 0.984 \\
\hline Circular Standard Deviation & $10.342^{\circ}$ \\
\hline Rayleigh Test $(\mathrm{Z})$ & 97.763 \\
\hline Rayleigh Test $(\mathrm{p})$ & $<1 \mathrm{E}-12$ \\
\hline
\end{tabular}

Table 4. Statistical analysis for Extract 2, 718-840 secs only.

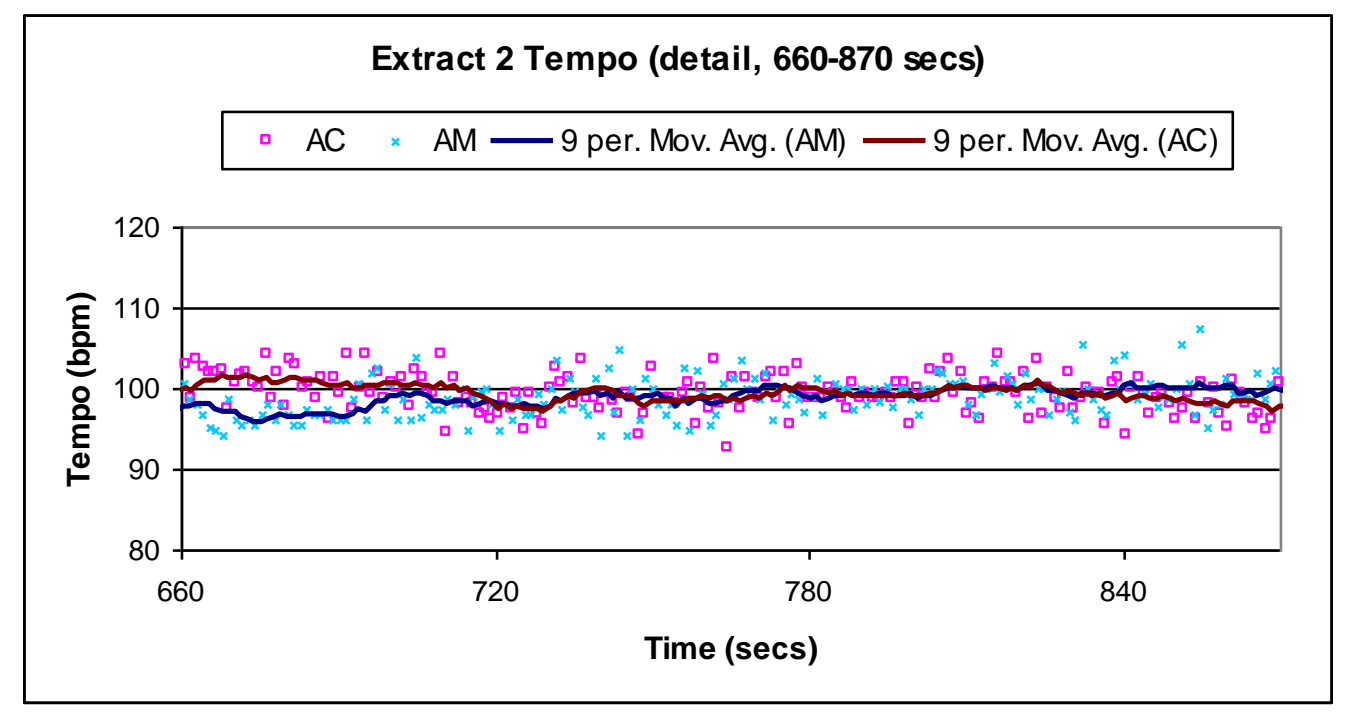

Figure 18. Tempo chart for Extract 2, 660-870 secs only, with trend lines.

Extract 3. Sunday afternoon: Jardim Industrial Congo and Justinopolis Congo pass each other

Recorded on 14th May 2006 from 4.23 pm; duration 4 mins 53 secs (293 secs)

This extract features a meeting between two visiting groups on the second afternoon, the Jardim Industrial Congo (JIC) and Justinopolis Congo (JC); JC features a female Captain who blows a whistle in time with 
the drums' rhythm instead of singing. This extract was chosen to enable study of entrainment (and its resistance) in an encounter between two Congo groups playing the same rhythmic pattern: Dobrado. The two groups meet on a path in the community while they both continue to play. The JC group is going uphill while JIC goes downhill towards the house of the main Captain of the Arturos community, Antônio Maria da Silva - more widely known as Seu Antonio - to greet him. ${ }^{[9]}$ The ritual greeting between two groups involves an exchange of salutations between the Captains, who hold each other's hand high and make the sign of the cross, while the banner of each group is passed over the heads of the other group's members. Normally both Captains would keep singing throughout the greeting. This case is unusual because the JC group's Captain uses a whistle rather than singing: during the greeting she drops the whistle and remains silent, while the JIC group's Captain continues to sing. It appears that JC play louder and faster as they approach JIC - possibly to help avoid entrainment to the other group. Moreover, during the greeting the two drummers playing at the front of both JIC and - even more strikingly - JC turn to face their own group, trying to avoid visual contact with the other community's Congo and to focus on their own team's fellow musicians.

The tempo chart (see Figure 19) shows that the JC group maintains a slightly higher tempo (117$124 \mathrm{bpm})$ than the JIC (108-104 bpm), ruling out any possibility of period and phase locking. This is supported by the relative phase time plot, which shows no stabilisation (see Figure 20). This analysis confirms that it is possible for two groups to play in close proximity for a sustained period without becoming entrained. It may also be significant that the JC tempo curve shows a slight increase over the course of the extract and the JIC plot a slight decrease: it could be that the groups maintained their separation by exaggerating the tempo difference. This, together with the attempt by the drummers to avoid visual contact with the other group, seems to be the main strategy at play.

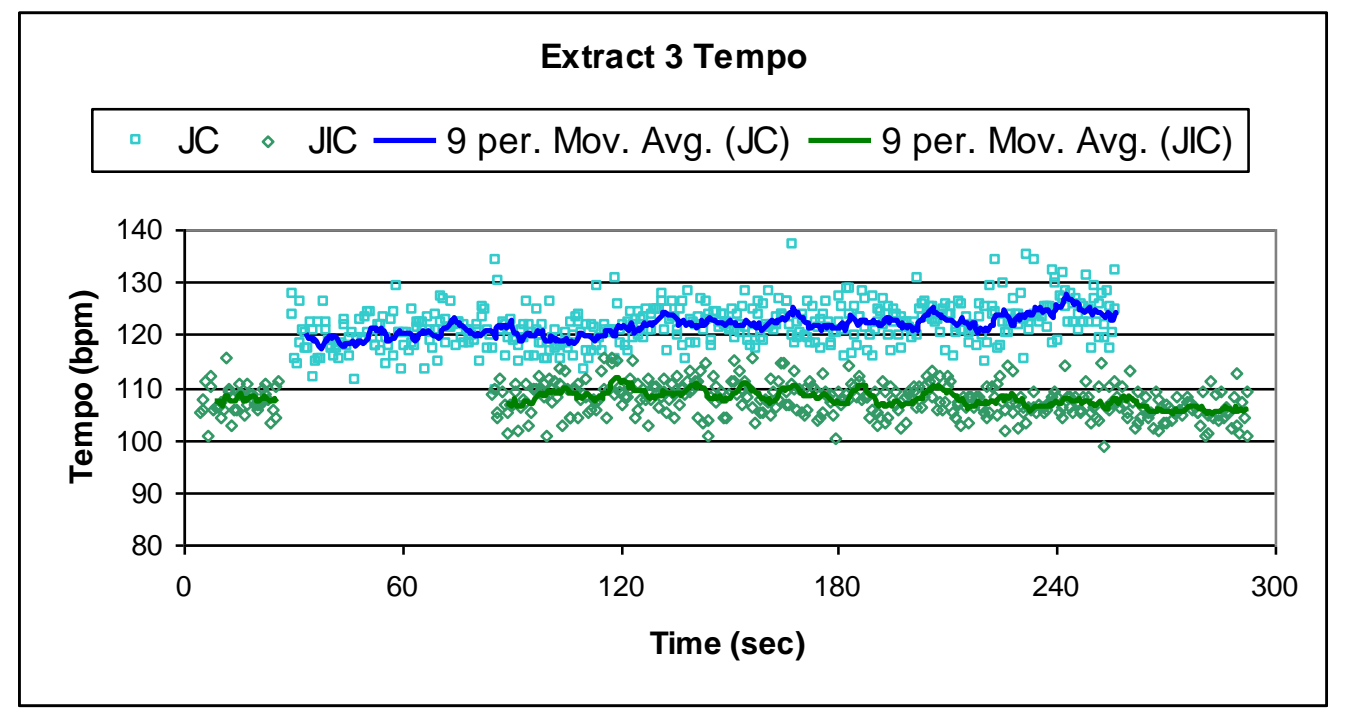

Figure 19. Tempo plot for Extract 3. 


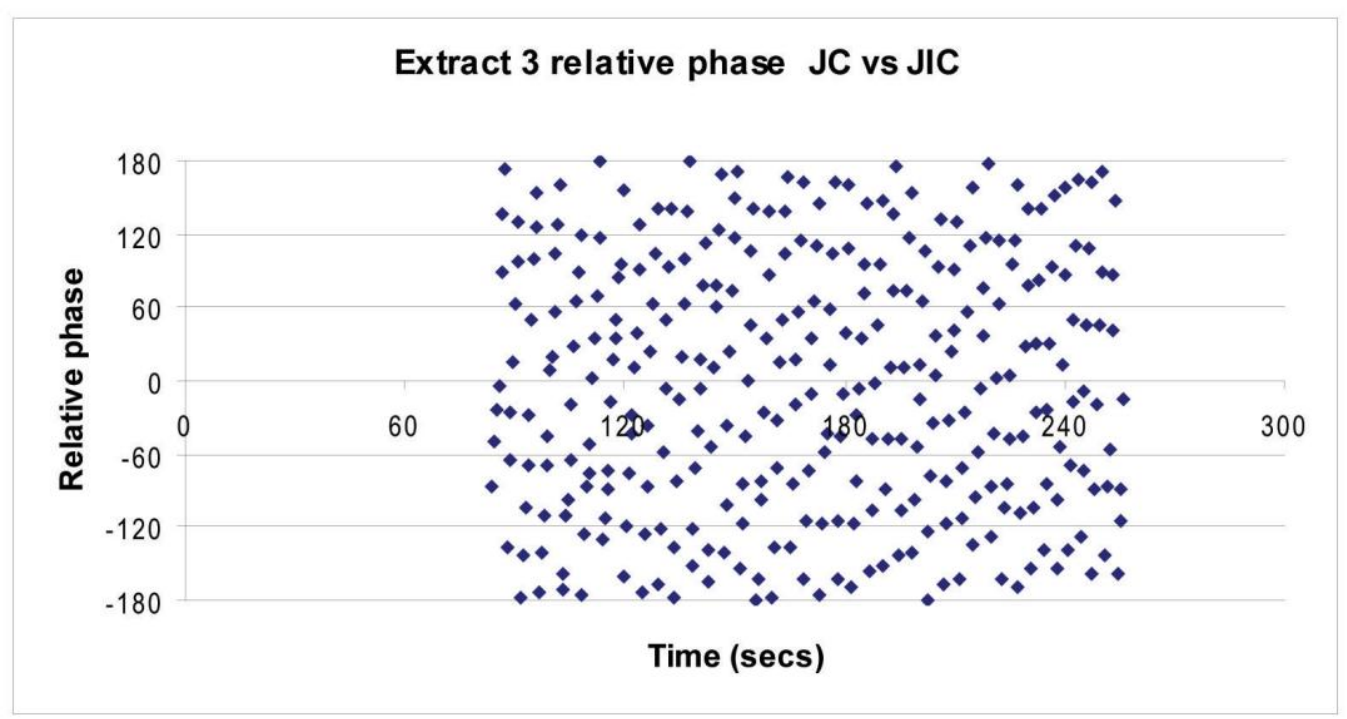

Figure 20. Relative phase plot for AM vs AC in Extract 3.

Extract 4. Sunday afternoon: Arturos Congo and Jardim Industrial Congo greet each other Recorded $14^{\text {th }}$ May 2006 from 4.41 pm; duration c. 8 min

This case study features one host group and one visiting group - AC and JIC - meeting and formally greeting each other near community elder Seu Antonio's house. Both groups knew we were interested in filming the greeting and were cooperating with us by carrying out a complete greeting ritual (see Figure 21). The extract starts with JIC performing outside Seu Antonio's house and greeting him. At the same point $\mathrm{AC}$ - who have just regrouped after a short rest - are emerging from the back of the same house while performing. AC pass by JIC and move uphill along the path; then the group turns and moves downhill facing Seu Antonio's house; finally they meet JIC, who in the meantime have completed the salutation of Seu Antonio and turned around. The two groups then exchange the ritual greeting. Afterwards, JIC walk uphill, while AC move towards Seu Antonio's house to salute him and take his blessing. Like the previous one, this extract was chosen to enable study of entrainment effects while the two groups play in close proximity and formally greet each other. 


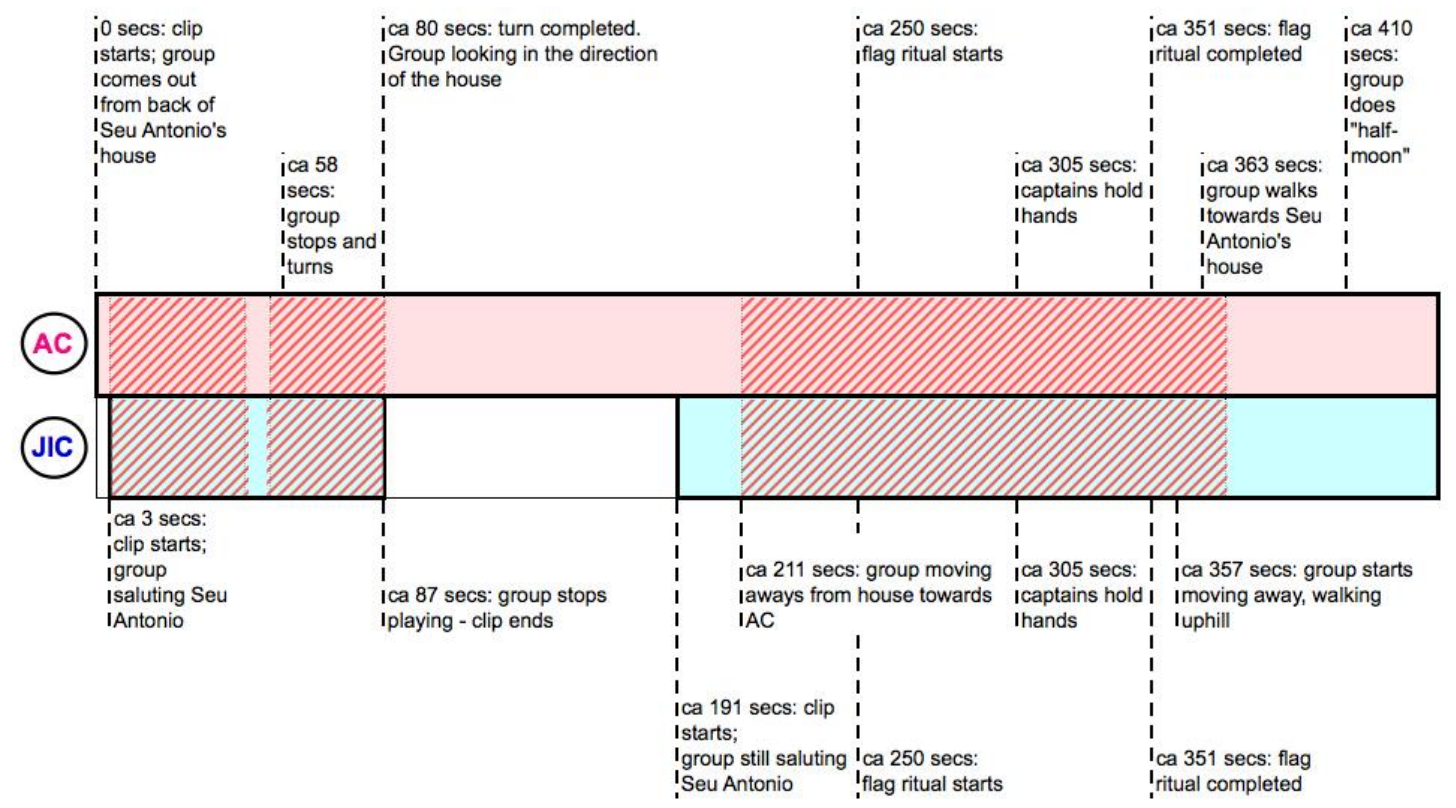

Figure 21. Summary diagram of the events of Extract 4. Red diagonal shading areas indicate periods of entrainment (cf. Figure 23).

The tempo plot (see Figure 22) shows that the two groups are playing at roughly the same tempo throughout the extract (106-110 bpm) until JIC starts to accelerate at around 370 secs: this happens once the greeting ritual is complete, at which point the group moves off uphill.

The relative phase plot (see Figure 23) shows considerable phase stabilisation until about 370 secs, the point at which JIC starts to accelerate and walks uphill. The position of the phase attractor shifts, however: it lies around $120^{\circ}$ for the first minute, followed by a possible stabilisation around $0^{\circ}$, followed (after a break in the data) by a long period of stabilisation around $-140^{\circ}$ (or $220^{\circ}$ ) or from about 210 secs to 370 secs (a period of about $2 \frac{1}{2}$ mins). These three phases of apparent stabilisation will now be analysed in turn.

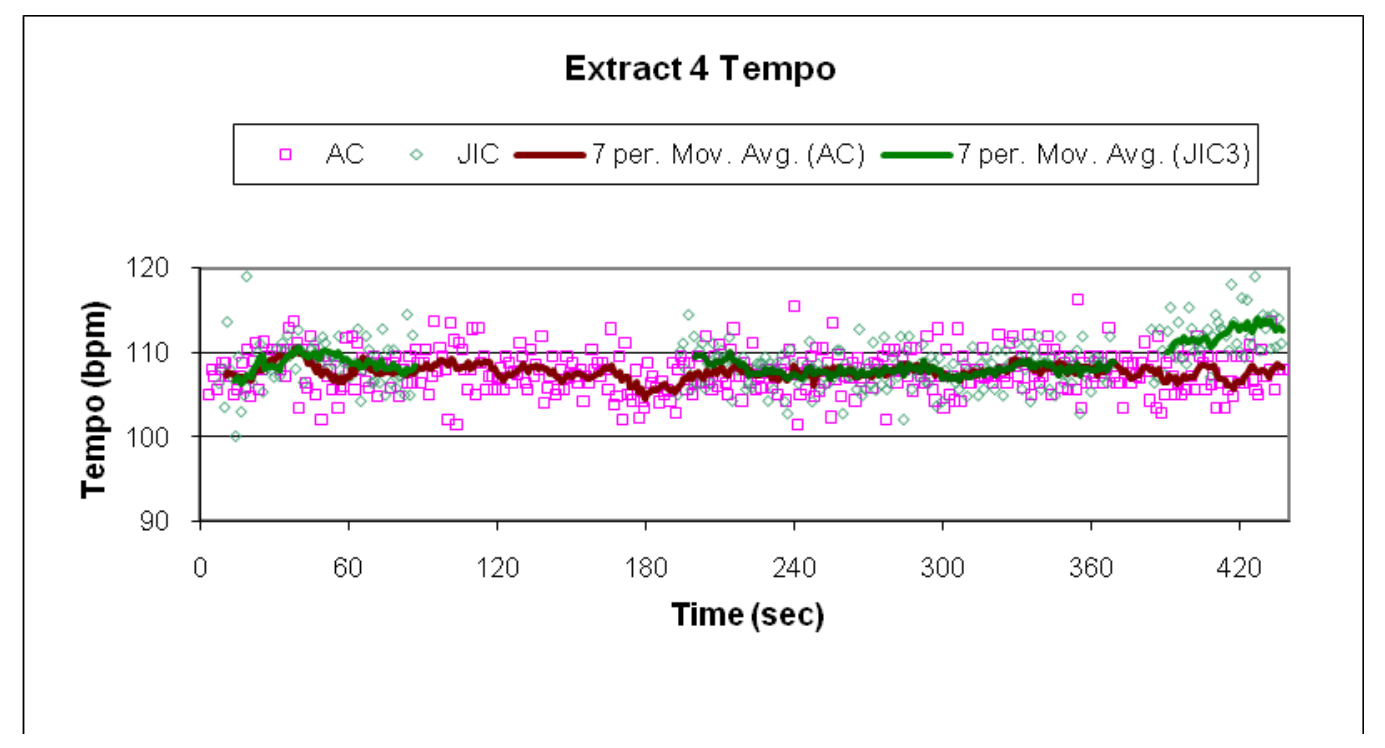

Figure 22. Tempo plot for Extract 4. 


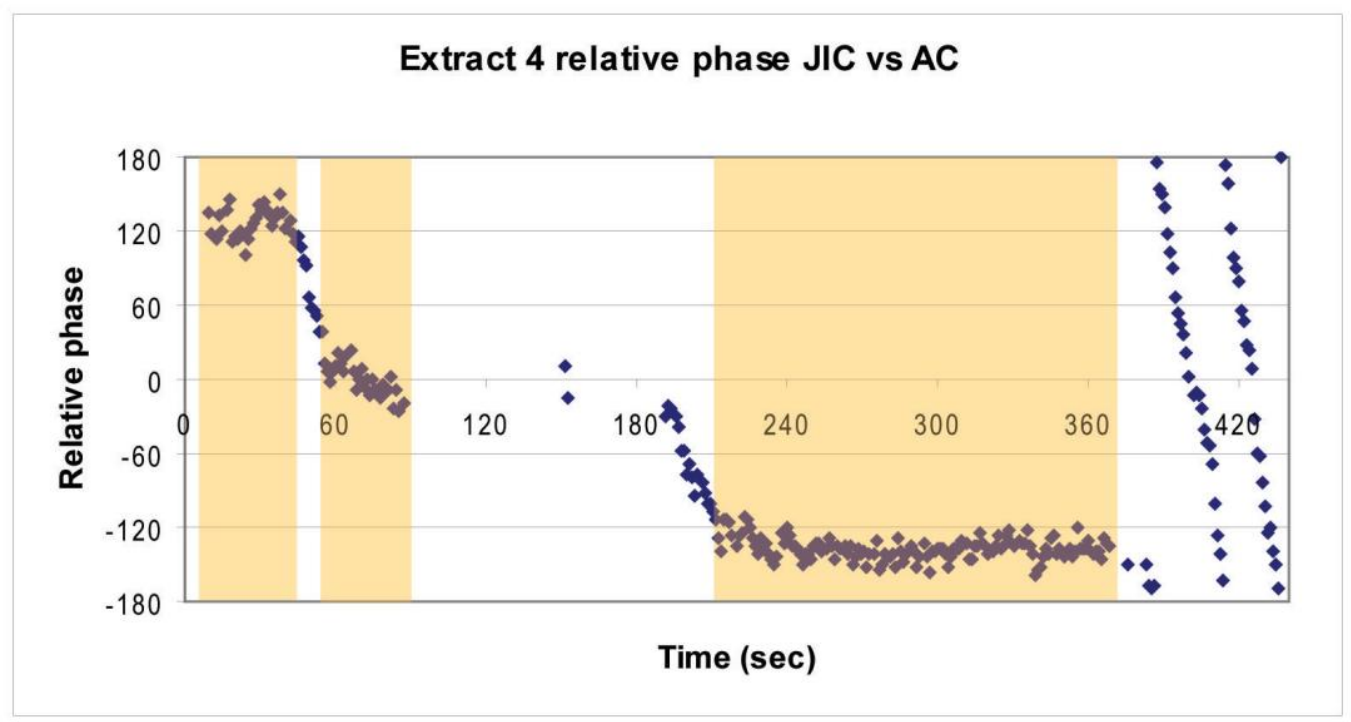

Figure 23. Relative phase plot for JIC vs AC in Extract 4. Shading indicates periods of phase stabilisation (cf. Figure 21).

\section{EXTRACT 4, FIRST PERIOD OF STABILISATION (0-46 SECS)}

The phase plots and statistical analyses for the first 46 secs of the clip indicate a period of entrainment with $\mu=124.854^{\circ}, r=0.979$ (see Figures 24 and 25, Table 5).

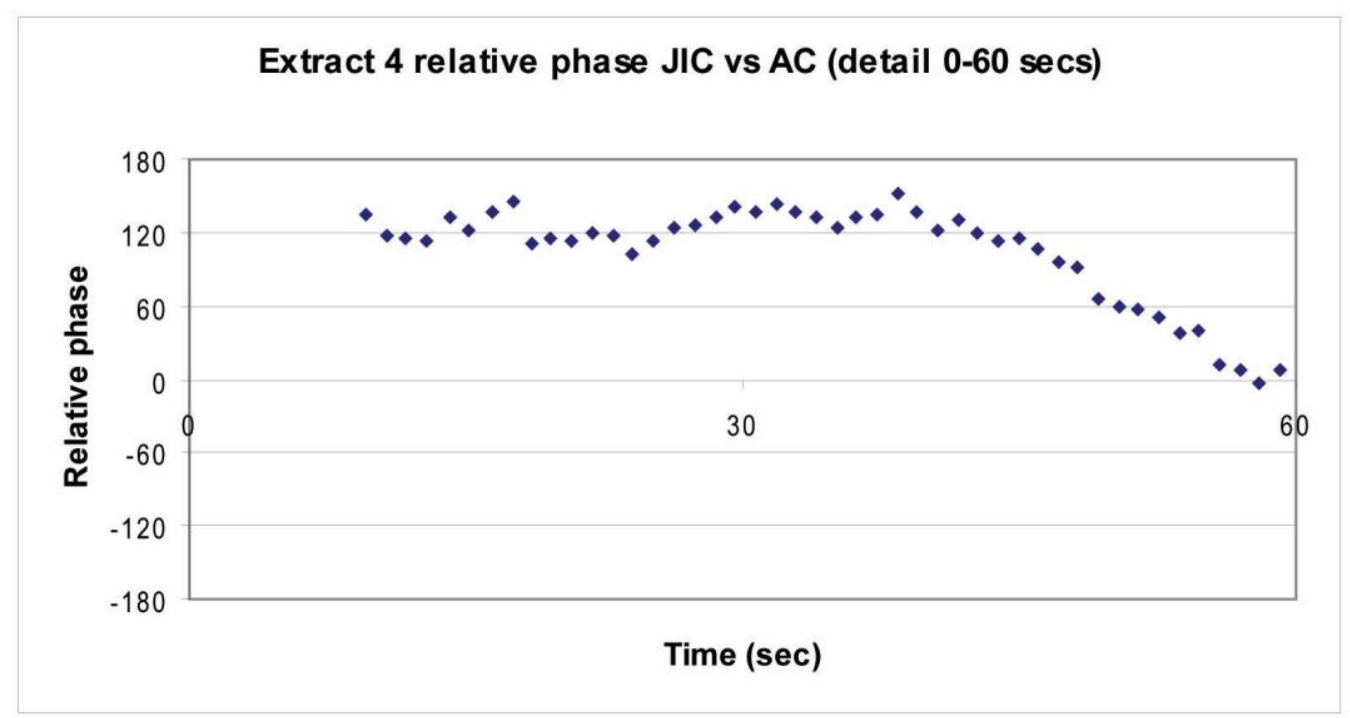

Figure 24. Relative phase plot for JIC vs AC in Extract 4, 0-60 secs only. 


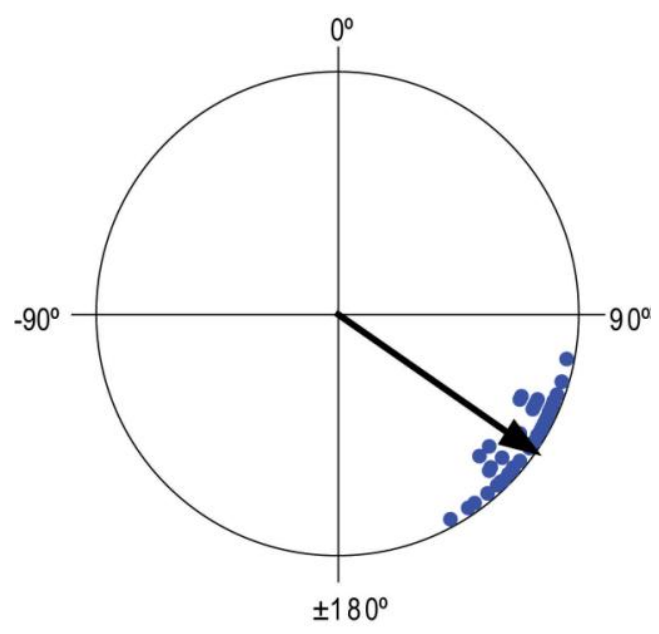

Figure 25. Circular plot of phase angles for Extract 4, 0-46 secs only.

\begin{tabular}{|l|l|}
\hline Number of Observations & 38 \\
\hline Mean Vector $(\mu)$ & $124.854^{\circ}$ \\
\hline Length of Mean Vector $(r)$ & 0.979 \\
\hline Circular Standard Deviation & $11.672^{\circ}$ \\
\hline Rayleigh Test $(\mathrm{Z})$ & 36.455 \\
\hline Rayleigh Test $(\mathrm{p})$ & $<1 \mathrm{E}-12$ \\
\hline
\end{tabular}

Table 5. Statistical analysis for Extract 4, 0-46 secs only.

\section{EXTRACT 4, SECOND PERIOD OF STABILISATION (55-87 SECS)}

The phase plots and statistical analyses for 55-87 secs of the clip indicate a period of entrainment with $\mu=$ $357.447^{\circ}\left(-2.553^{\circ}\right), r=0.971$ (see Figures 26 and 27, Table 6). The data immediately following this point is missing, so we cannot confirm how long the groups remained entrained around $0^{\circ}$.

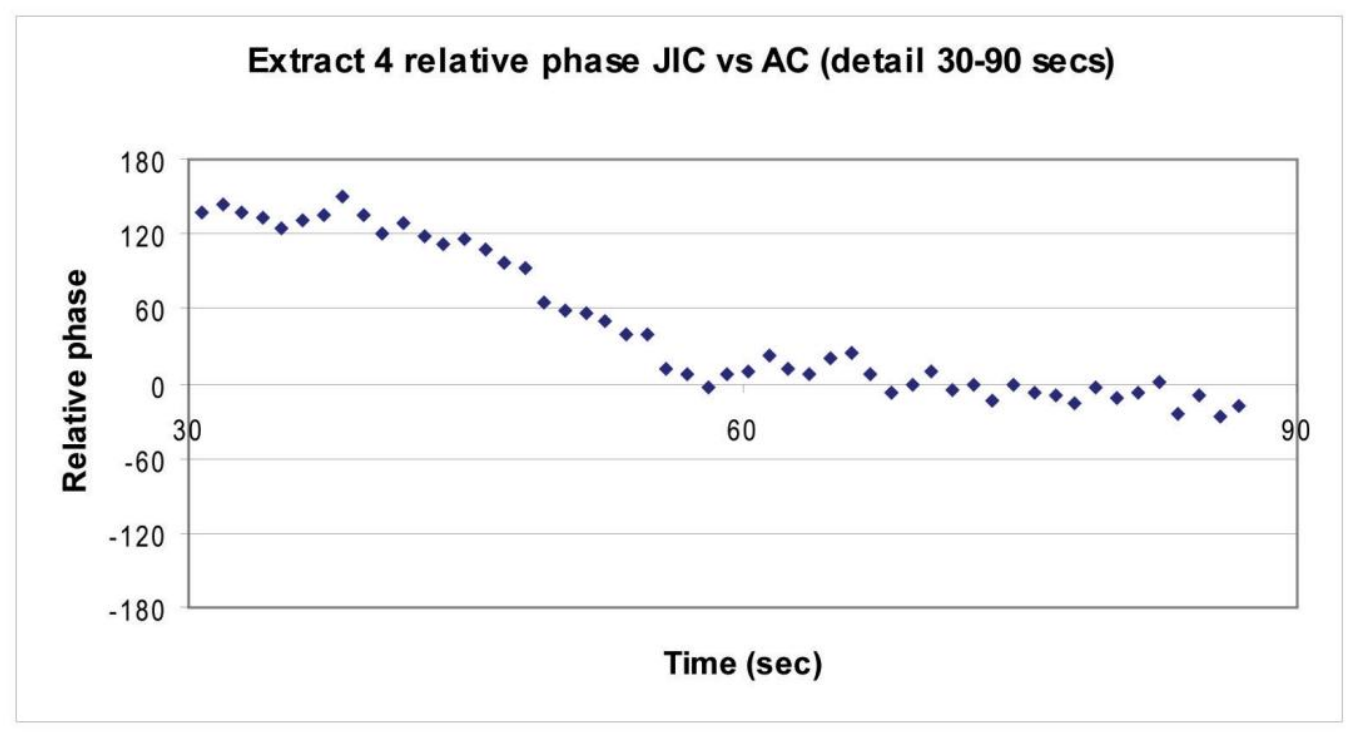

Figure 26. Relative phase plot for JIC vs AC in Extract 4, 30-90 secs only. 


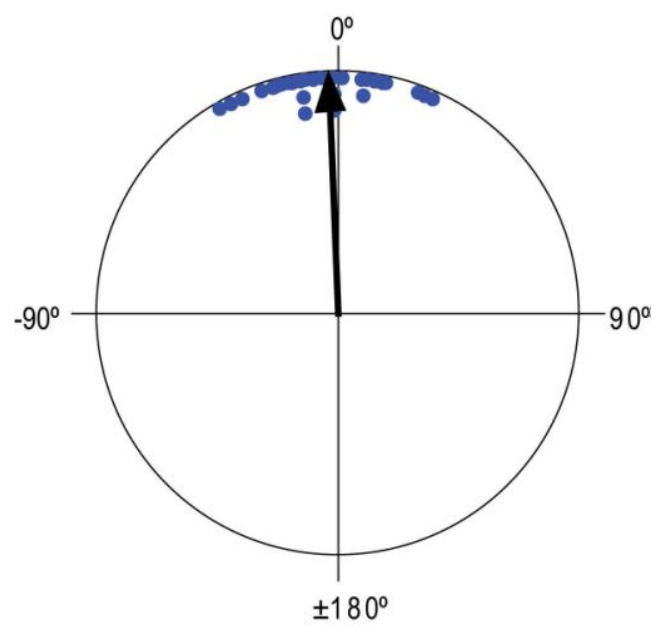

Figure 27. Circular plot of phase angles for Extract 4, 55-87 secs only.

\begin{tabular}{|l|l|}
\hline Number of Observations & 29 \\
\hline Mean Vector $(\mu)$ & $357.447^{\circ}$ \\
\hline Length of Mean Vector $(r)$ & 0.971 \\
\hline Circular Standard Deviation & $13.919^{\circ}$ \\
\hline Rayleigh Test $(Z)$ & 27.338 \\
\hline Rayleigh Test $(p)$ & $1.31 \mathrm{E}-11$ \\
\hline
\end{tabular}

Table 6. Statistical analysis for Extract 4, 55-87 secs only.

\section{EXTRACT 4, THIRD PERIOD OF STABILISATION (211 - 368 SECS)}

The phase plots and statistical analyses for 211-368 secs indicate a period of entrainment with $\mu=223.184^{\circ}$ $\left(-136.816^{\circ}\right), r=0.988$ (see Figures 28 and 29, Table 7). The two groups have clearly entrained in a stable relationship, but out of phase, with $\mathrm{JIC} 223^{\circ}$ behind (or $137^{\circ}$ ahead of) AC. To reinforce this point graphically, Figure 30 shows the tempo chart for the same period: the two moving average trend lines clearly track each other closely from about 211-368 secs (using the correlation analysis above, Pearson = $0.393, \mathrm{p}<0.01)$.

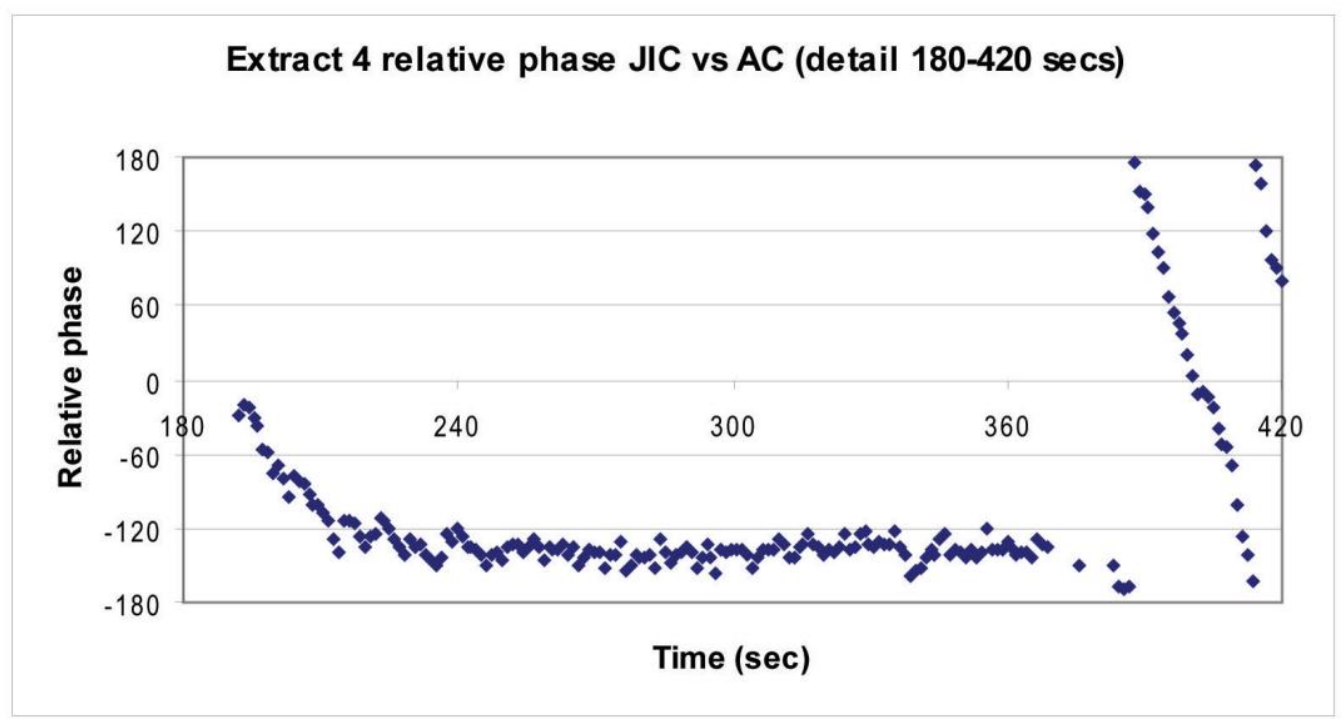

Figure 28. Relative phase plot for JIC vs AC in Extract 4, 180-420 secs only. 


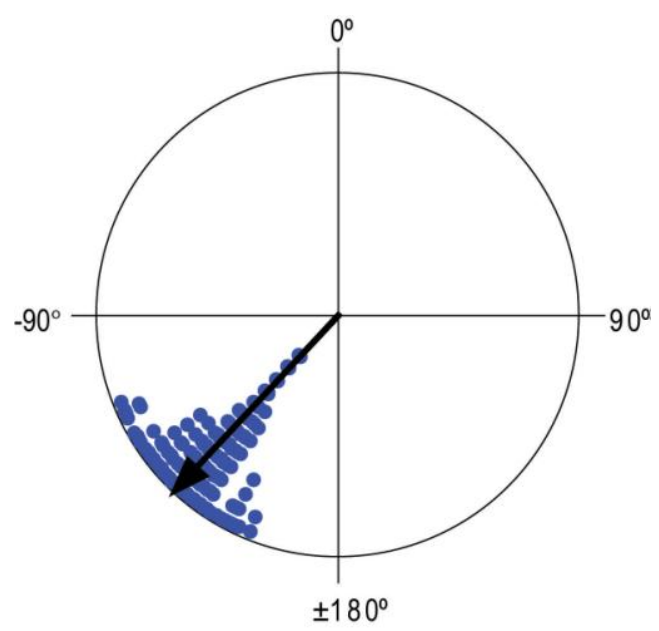

Figure 29. Circular plot of phase angles for Extract 4, 211-368 secs only.

\begin{tabular}{|l|l|}
\hline Number of Observations & 142 \\
\hline Mean Vector $(\mu)$ & $223.184^{\circ}$ \\
\hline Length of Mean Vector $(r)$ & 0.988 \\
\hline Circular Standard Deviation & $8.876^{\circ}$ \\
\hline Rayleigh Test $(\mathrm{Z})$ & 138.633 \\
\hline Rayleigh Test $(\mathrm{p})$ & $<1 \mathrm{E}-12$ \\
\hline
\end{tabular}

Table 7. Statistical analysis for Extract 4, 211-368 secs only.

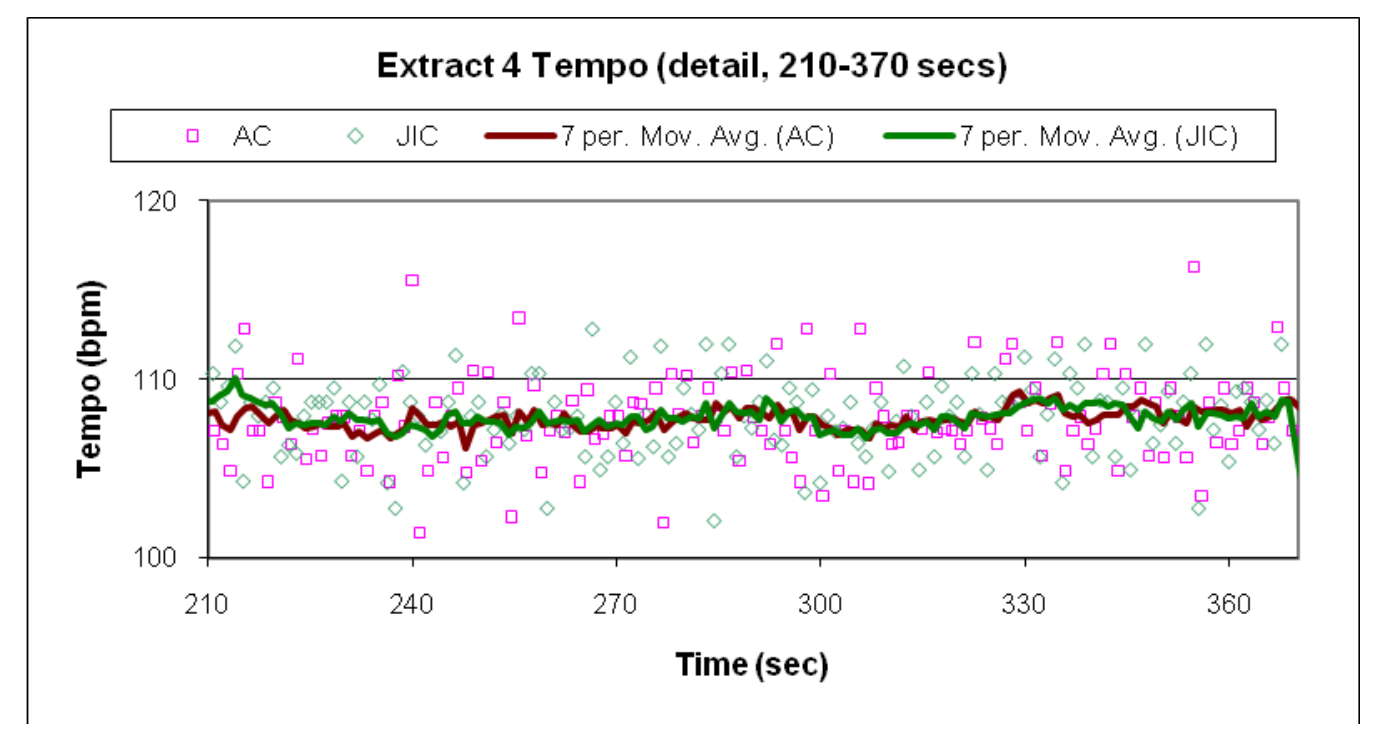

Figure 30. Tempo plot for Extract 4, 210-370 secs only.

\section{SUMMARY OF EXTRACT 4 ANALYSES}

The two groups certainly stabilise at $223^{\circ}\left(-137^{\circ}\right)$ : they appear to stabilise at about $125^{\circ}$ at the start of the clip, and also - although missing data means that we cannot confirm for how long - almost in phase at around $357^{\circ}\left(-3^{\circ}\right)$. Why should these particular phase angles be stable? In order to investigate this question we carried out a further set of tapping runs to determine the perceived position of the $2^{\text {nd }}$ and $3^{\text {rd }}$ main beats of the Dobrado rhythm for each of the two groups, expressed in terms of phase difference from beat one (see Figure 31). 


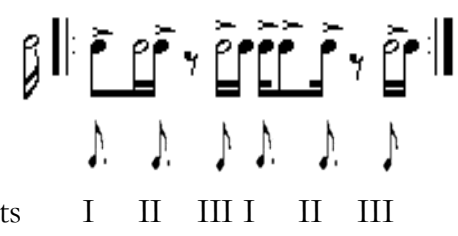

Figure 31. Dobrado rhythmic pattern highlighting its main strokes (I, II and III)

The results are summarised in Table 8. For AC the second and third beats fall at $121^{\circ}$ and $258^{\circ}$ respectively; for JIC they fall at $119^{\circ}$ and $252^{\circ}$. Had the rhythm been an equal three-beat pattern these angles would have been $120^{\circ}$ and $240^{\circ}$; had it been a precise $3+3+2$ pattern, they would have been $135^{\circ}$ and $270^{\circ}$. The patterns are therefore somewhat closer to the equal three-beat model than they are to a $3+3+2$, but with the $3^{\text {rd }}$ beat delayed.

\begin{tabular}{|l|l|l|l|l|}
\hline Variable & AC 2nd beat & AC 3rd beat & JIC 2nd beat & JIC 3rd beat \\
\hline $\begin{array}{l}\text { Number of } \\
\text { Observations }\end{array}$ & 389 & 389 & 202 & 202 \\
\hline Mean Vector $(\mu)$ & $120.955^{\circ}$ & $257.645^{\circ}$ & $119.354^{\circ}$ & $252.287^{\circ}$ \\
\hline $\begin{array}{l}\text { Length of Mean } \\
\text { Vector }(r)\end{array}$ & 0.996 & 0.998 & 0.983 & 0.968 \\
\hline
\end{tabular}

Table 8. Summary statistics for the positions of the perceived second and third beats relative to that of the first beat of the JIC and AC groups, Extract 4.

Given these two groups' rhythms, what is the significance of the phase differences of $125^{\circ}$ and $223^{\circ}$ ? This can easily be seen if the rhythms are visualised as circles and then overlaid (Figure 32). If the rhythms are played almost exactly in phase, they are obviously highly congruent; out of phase by $125^{\circ}$ they are also well matched, with a phase difference of $17^{\circ}$ between JIC's beat 3 and AC's beat 1 . With a phase difference of $223^{\circ}$ we can again see that two of the three pairs of beats 'match up', but that the third pair (JIC's beat 1 and AC's beat 3 ) shows a significant discrepancy of $34^{\circ}$. It appears therefore that the angle of $223^{\circ}$, which is that sustained for the longest confirmed period, combines stability ( 1 of the 3 beat pairs is closely synchronised) with an audible difference (another pair of beats is clearly out of time with each other). 


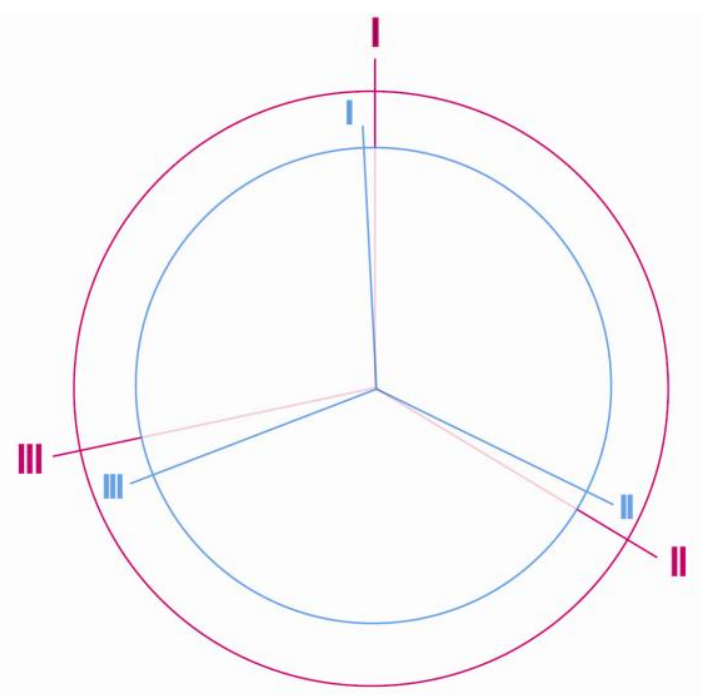

$\mathrm{AC}$ and $\mathrm{JIC}$ in phase

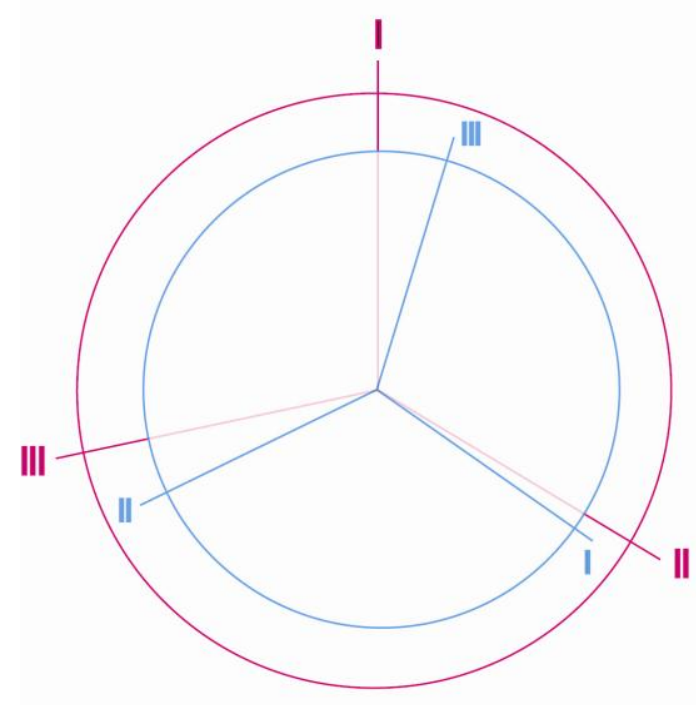

JIC $125^{\circ}$ behind AC

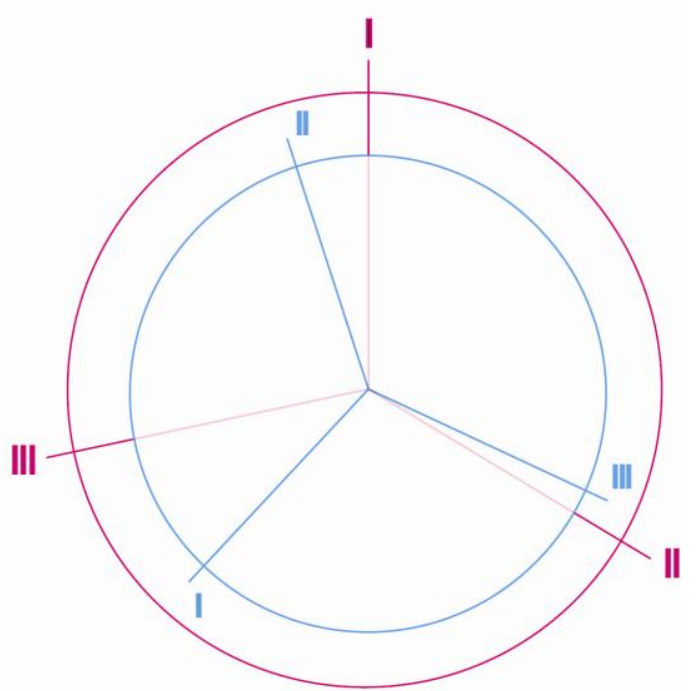

JIC $223^{\circ}$ behind AC

Figure 32. A visualisation of the phase relationship between AC (outer circle, pink) and JIC (inner circle, blue). With phase differences of $125^{\circ}$ and $223^{\circ}$ beat II of AC is close to one of the other beats of JIC's pattern, while the other pairs of beats are further apart - especially AC III vs JIC I in the $223^{\circ}$ position. The 'in phase' relationship is drawn at $357^{\circ}$, which is the mean phase angle calculated.

\section{SUMMARY OF RESULTS}

The main findings of the analyses of these four extracts can be summarised briefly as follows:

1. Extract 1

Two groups - Congo and Moçambique - belonging to the host community of Arturos pass each other, one actually walking between the lines of the other. The two groups become entrained, in phase, approximately 20 seconds before they pass each other, just after they have turned to face each other and made visual contact. The Moçambique group, whose tempo tends to increase when playing this Serra 
Acima rhythm, accelerates until it matches the tempo of the Congo group and then stabilises as the two groups entrain. The entrainment is lost as the two groups move apart, but re-established as the Congo group turns to face the Moçambique group once more: now the coupling is somewhat weaker, however, and the two groups are physically further apart.

\section{Extract 2}

The same two Arturos' groups play in close proximity at a climactic point in the ritual. Whereas in the Moçambique's previous song it had accelerated almost to the tempo of the Congo but not entrained, in this song it does reach Congo's tempo: the two groups effectively lock together in phase at this common tempo and remain tightly entrained for about $2 \frac{1}{2} 2$ mins.

\section{Extract 3}

Two guest Congo groups pass each other on one of the community's pathways and exchange ritual greetings. The group with the faster tempo accelerates slightly and plays louder, while that with the slower tempo decelerates slightly, while each group's drummers try to avoid visual contact with the other group. The two groups do not entrain.

4. Extract 4

Two Congo groups, one of the host community and one a guest, meet each other and carry out a formal greeting ritual. Most of the time during which the greeting is being prepared and then carried out, the two groups are entrained. However, the phase relationship between them shifts between three different positions. The longest period of stability, which coincides to the greeting itself, is out of phase by $223^{\circ}$. Analysis of the rhythmic patterns confirms that in this position one of the three main beats of the two Dobrado patterns coincide, but the others clash noticeably.

\section{DISCUSSION}

These analyses suggest a number of factors which influence the occurrence of inter-group entrainment in Congado.

Proximity and Visual contact.

In each case in which entrainment took place, the two groups were in close proximity: in Extract 1, moreover, it is worth repeating that the coupling is stronger when the two groups are closer together. In Extract 3 there is proximity but not entrainment: proximity therefore seems to be a necessary but insufficient condition for entrainment. Visual contact also seems to be important. In the first extract the two groups became entrained shortly after they faced each other and made visual contact, but some 20 secs before they physically passed each other. The point at which they make visual contact does not correspond, as far as we can determine, to any other change which would have resulted in the two groups being in stronger auditory contact. Although not conclusive in itself, this observation is consistent with other studies which have identified the role of visual attention in unintended interpersonal entrainment (Schmidt \& O'Brien, 1997; Richardson et al., 2005, 2007). In the third extract, when the two groups managed to resist entrainment, one of the strategies at play appears to be to avoid visual contact with the other group.

Similarity of tempo.

All the cases of entrainment observed here are in a 1:1 tempo relationship. In the fourth extract the two groups' tempi are close throughout and they become entrained. In the first two examples one group has a tendency to accelerate and the other to keep a more stable tempo (sometimes decelerating slightly), which means that the tempi are very likely to cross at various points, creating opportunities for entrainment. In the third clip, when the two groups do not become entrained, there is a significant tempo difference which is exaggerated by the groups as they meet.

Intention.

When two groups of the same community meet, we take it from ethnographic data that they are not attempting to resist entrainment. In both such cases examined here the two groups became strongly entrained, in phase, when playing in close proximity. When two groups belonging to different communities meet, on the other hand, we may assume that they are attempting to prevent entrainment. In one of the two cases examined here the groups successfully avoided entrainment. In the other they did become entrained, but for much of the time they remained out of phase. It seems probable that they were not aware that they had become entrained, as was suggested by participants we interviewed later. 
This study confirms several findings of previous work in entrainment. First, as noted above, a number of studies have shown the importance of visual focus in interpersonal entrainment. Secondly, the coupling force necessary to entrain two oscillators is weaker if the difference between their periods is small, so we would expect that groups close in tempo will entrain more easily. Thirdly, intention is less frequently considered in entrainment studies, but these findings are consistent with Kelso's (1995, p. 147) suggestion that "one may construe intention as specific information acting on or perturbing the basic (intrinsic) coordination dynamics". In this case, we may identify 'intrinsic' dynamics in the systems formed by the coupling of the groups - coupling which is mediated by aural and visual attention. The intentions of participants to either allow or resist entrainment, manifested in the attempt to concentrate attention as much as possible on one's own group, act upon these intrinsic dynamics.

There is no fundamental difference between the dynamics of intra-group and inter-group entrainment, each of which involves the coordination of autonomous rhythmic entities. Awareness of the inter-group level is potentially important in musical entrainment studies, nonetheless. First, although they are rarely considered by academic researchers, events involving multiple co-present groups are in fact not uncommon around the world. Sometimes this is necessary for ritual purposes, as in Congado; think also of processions, or of sections of rival supporters in a crowd at a sporting event. Second, we might consider in larger ensembles (such as orchestras) whether the entrainment dynamics are best considered on two levels, intra-group (e.g. within the string section) and inter-group (cf. Maduell \& Wing, 2007, on flamenco).

We have also attempted to demonstrate the usefulness of ethnography in directing and shaping the empirical analysis of real-world events. Ethnography not only contributes by providing contextual data, but also helps to reduce the observer's cultural bias, thus enabling observation and interpretation to be more closely oriented by the specific ways through which the people whose musical processes are being studied perceive and experience reality. In this study, although the detailed claims regarding the occurrence of entrainment are based on a rigorous quantitative analysis, this analysis would not have been possible without both a detailed knowledge of the musical repertoire and an equally deep understanding of the ritual context. In turn, the empirical analysis produced results that were not otherwise obvious or even suspected, and we were able to discuss these results with participants in the ritual and further enrich the ethnographic study. The study as a whole can therefore be regarded as a case study in the interaction between ethnographic and quantitative modes of enquiry.

\section{ACKNOWLEDGEMENTS}

The authors would like to thank:

Udo Will and Ed Large for their advice on the entrainment analysis and their helpful comments on the text, Devin McAuley for his circular statistics workbook, and other members of the Entrainment Network for their comments on our presentations. Any errors in the final text are of course our responsibility alone.

Rafael Anderson Guimarães Santos, André Lucas Guimarães, Leonardo Pires Rosse, Maria Luiza Ramos, and Marília Rocha de Siqueira for their assistance with fieldwork and analysis.

All the members of the Arturos community of Contagem, who hosted the event analysed in these pages and who helped us throughout our work in the field, and especially Antônio Maria da Silva, José Bonifácio da Luz, Mário Braz da Luz, Izaíra Maria da Silva, and Maria do Rosário da Silva.

The members of Jardim Industrial's Congo group for their assistance during the festival and during the analysis phase, with special thanks to Ivan Coelho de Jesus.

This research was carried out thanks to the generous support of the Open University and of the British Academy (grant references VF2007/45694 and SG44106).

\section{NOTES}

[1] Devotees of Our Lady, whether congadeiros or not, may ask to pay promises during Congado rituals. One at a time, these people normally follow one group around the chapel, dressed with Royal crown and mantle.

[2] Martin Clayton, Rafael Anderson Guimarães Santos, Laura Leante, Glaura Lucas, Leonardo Pires Rosse, and Marília Rocha de Siqueira. 
[3] This was done using a circular statistics spreadsheet prepared by Devin McAuley.

[4] By 'phase attractor' we mean a certain phase relationship to which the entrained system tends, and around which it tends to stabilise: this is not always at or close to $0^{\circ}$ (in phase). By 'strength of coupling' we mean the degree to which the two rhythms (i.e. the two groups) are entrained, ranging from 0 (the two groups are rhythmically entirely independent of each other) to 1 (the two groups are not at all independent).

[5] The "half moon" is a turn-around movement which Congo groups perform in certain circumstances. It involves the two lines of Congo performing a "u-turn" (hence the "half-moon shape") by crossing one another; once all players and dancers have completed it, they repeat it in order to go back to their original positions.

[6] Since each circle represents an individual data point, concentrations of data points within certain ranges result in data points stacking up.

[7] This acceleration was described as follows by the Captain of the group:

"Every time I sing this song, I sing it in a very harmonious way, very slow. But as the song develops it seems that the people who go singing the response, it seems that they obtain a kind of energy, and then there's a tendency for this song to accelerate. And it's not only an acceleration of the rhythm, it's as if something strengthened all of us and gave us a greater motivation for the group, in such a way that we feel the music is so important at that moment, that we let the feelings take over. And in that example, there is an intention to accelerate the music, but this acceleration happens in all aspects, not only rhythmic, you know. It's the way we sing, the way we dance. It is as if there was an energy that comes and passes through our body and totally modifies the tempo the music was supposed to have. And this does not happen only with this song, but also with many other songs that have the same tempo, the same meaning. But, as the song develops, as we go singing it, it goes through this acceleration, let's say, spontaneously" (Jorge Antônio dos Santos - interview on October $\left.20^{\text {th }}, 2007\right)$.

[8] Jorge Antônio dos Santos - interviewed by Lucas on October 20 ${ }^{\text {th }}, 2007$.

[9] Antônio Maria da Silva is Arthur's son.

\section{REFERENCES}

Clayton, M. R. L. (2007). Observing entrainment in Indian music performance: Video-based observational analysis of tanpura playing and beat marking. Musicae Scientiae, Vol. 11, No. 1, pp. 27-60.

Clayton, M. R. L., Sager, R., \& Will, U. (2005). In time with the music: the concept of entrainment and its significance for ethnomusicology. European Meetings in Ethnomusicology, Vol. 11 (ESEM Counterpoint, 1), pp. 3-75.

Doffman, M. R. (2008) Feeling the groove: Shared time and its meanings for three jazz trios. Ph.D. Dissertation, Music Department, Open University.

Eck, D. (2002). Finding downbeats with a relaxation oscillator. Psychological Research, Vol. 66, pp. 1825.

Jones, M. R., \& Boltz, M. (1989). Dynamic attending and responses to time. Psychological Review, Vol. 96, No. 3, pp. 459-491.

Kelso, J. A. S. (1995). Dynamic patterns: The self-organization of brain and behavior. Cambridge, Mass. : MIT Press.

Large, E. W. (2000). On synchronizing movements to music. Human Movement Science, Vol. 19, pp. 527566. 
Large, E. W., \& Jones, M. R.. (1999). The dynamics of attending: How people track time-varying events. Psychological Review, Vol. 106, No. 1, pp. 119-159.

Large, E. W., \& Kolen, J. F. (1994). Resonance and the perception of musical meter. Connection Science: Journal of Neural Computing, Artificial Intelligence and Cognitive Research, Vol. 6, No. 2-3, pp. 177-208.

London, J. (2004). Hearing in time: Psychological aspects of musical meter. New York and Oxford: Oxford University Press.

Lucas, G. (2002a). Musical rituals of Afro-Brazilian religious groups within the ceremonies of Congado. Yearbook for Traditional Music, Vol. 34, pp. 115-127.

Lucas, G. (2002b). Os Sons do Rosário: o Congado Mineiro dos Arturos e Jatobá. Belo Horizonte: Editora UFMG.

Lucas, G. (2005). Música e Tempo nos Rituais do Congado Mineiro dos Arturos e do Jatobá. Ph.D. dissertation. Universidade Federal do Estado do Rio de Janeiro.

Maduell, M., \& Wing, A. (2007). The dynamics of ensemble: The case of flamenco. Psychology of Music, Vol. 35, No. 4, pp. 591-627.

Richardson, M. J., Marsh, K. L., \& Schimdt, R. C. (2005). Effects of visual and verbal interaction on unintentional interpersonal coordination. Journal of Experimental Psychology: Human Perception and Performance, Vol. 31, No. 1, pp. 62-79.

Richardson, M. J., Marsh, K. L., Isenhower, R. W., Goodman, J. R. L., \& Schmidt, R. C. (2007). Rocking together: Dynamics of intentional and unintentional interpersonal coordination. Human Movement Science, Vol. 26, pp. 867-891.

Schmidt, R. C., \& O’Brien, B. (1997). Evaluating the dynamics of unintended interpersonal coordination. Ecological Psychology Vol. 9, No. 3, pp. 189-206. 